\title{
PRUEBA, INMEDIACIÓN Y POTESTADES EN EL PROCESO LABORAL: OBSERVACIONES CRÍTICAS Y APELACIÓN AL EQUILIBRIO*
}

\author{
Diego Palomo Vélez ${ }^{*}$ \\ Pedro Matamala SOUPER ${ }^{* *}$
}

RESUMEN: La reforma procesal laboral impuso una serie de cambios de la mano de la opción por la oralidad en los juicios. El propósito de este trabajo es efectuar una revisión crítica de los principales cambios, que huya de la autocomplacencia que hasta ahora se ha instalado en la doctrina que ha mostrado interés en este nuevo modelo, especialmente la laboral. En el trabajo se sostiene que junto con el logro de aspectos muy positivos para el mejor desempeño de la Justicia laboral, la reforma ha servido para la instalación de una serie de problemas que han significado un retroceso para la situación de elementos esenciales de la noción de todo proceso. Se aborda la situación de los procesos por audiencias, especialmente la situación de las audiencias preparatorias y de juicio al servicio de la actividad probatoria, el papel reforzado de los jueces y las restricciones derivadas del nuevo recurso de nulidad laboral.

PALABRAS CLAVE: Juicio laboral - oralidad - prueba - jueces - recursos.

\section{PROOF, IMMEDIACY AND POWERS IN THE LABOR PROCESS: CRITICAL OBSERVATIONS AND APPEAL TO BALANCE}

ABSTRACT: The labor reform imposed a series of changes due to the option of oral arguments. The purpose of this work is to make a critical review of the major changes, to put aside the self-indulgence that has

\footnotetext{
* El trabajo forma parte de Proyecto Fondecyt Regular 2012 N$^{\circ} 1120409$, "Estudio crítico del nuevo proceso laboral chileno a la luz de las exigencias del derecho al debido proceso". Proyecto dirigido por el profesor Dr. Diego Palomo Vélez.

Fecha de recepción: 13 de mayo de 2012.

Fecha de aceptación: 21 de noviembre de 2012.

** Abogado, profesor de Derecho Procesal en la Universidad de Talca, Magíster y Doctor en Derecho por la Universidad Complutense de Madrid. Correo electrónico: dpalomo@utalca.cl

*** Abogado, profesor de Litigación oral en la Universidad de Talca, Magíster en Derecho del Trabajo por la Universidad de Talca. Correo electrónico: pedro.matamala@hmv.cl
} 
been installed in the doctrine that has shown interest in this new model, especially the labor field.

The paper states that together with the most positive aspects related to the best performance of the laboral justice, the reform has been useful to install a number of problems which have meant a setback of the essential elements of the notion of any process. It addresses the situation of the processes by audiences, especially the situation of preparatory hearings and judgment to the service of the probation activity, the enhanced role of judges and the limitation derived from the new motion of laboral nullity.

KEY WORDS: Labor lawsuit - orality - evidence - judges - remedies.

\section{1) LOS PROCESOS POR AUDIENCIAS, LA RECUPERACIÓN DE LA FIGURA DEL JUEZ Y LA REVALORIZACIÓN DE LA PRUEBA}

La evolución de los procedimientos nacionales muestra desde hace una década una clara tendencia hacia la recepción de modelos procesales construidos en torno a la idea símbolo de la oralidad, a la cual se ha impuesto el tremendo desafío de modernizar un servicio judicial que estaba atrapado en los problemas de un sistema escriturado, claramente ineficiente en los tiempos y cuestionado respecto a la calidad de una respuesta jurisdiccional entregada por un juez que no había tenido efectivo contacto con el material probatorio incorporado al proceso, dada la generalizada delegación de funciones instalada como algo natural y aceptado en la lógica del señalado modelo de enjuiciamiento.

De esta tendencia resultan ser vivos ejemplos no solo el procedimiento penal (que la inaugura), el procedimiento de familia (leyes 19.968 y 20.286), y el proyectado nuevo Código procesal civil, que recoge los principios que desde hace más de un siglo se han venido postulando (Chiovenda) y aplicando en el mundo para la mejora de la Justicia civil ${ }^{1}$, sino

Véase al respecto: Chiovenda, G. "L'oralitá e la prova". Rivista di Diritto Processuale Civile, Vol. I, 1924; Denti, V. "Chiovenda y las reformas del proceso civil". En: Sendra, V. y otros (Coords.). Estudios de Derecho Procesal en honor de Victor Fairén Guillén. Valencia: Ed. Tirant lo Blanch, 1990; Cappelletti, M. "Processo orale e processo scritto nel mondo contemporaneo". En: Cappelletti, M. Giustizia e Societá. Milano: Edizioni di Comunitá, 1972; Montero, J. Los principios políticos de la nueva Ley de Enjuiciamiento Civil: los poderes del juez y la oralidad. Valencia: Ed. Tirant lo Blanch, 2001; Taruffo, M. "Oralidad y escritura como factores de eficiencia en el proceso civil". En: Carpi, F.; Ortells, M. Oralidad y escritura en un proceso civil eficiente. Valencia: Universidad de Valencia, 2008; Trocker, N.; VARANo, V. (Coords.). The reforms of civil procedure in comparative perspective. Turín: Ed. Giappichelli, 2005; Nieva, J. "Los problemas de la oralidad". Revista justicia, Nº 1-2, 2007; Nieva, J. "Oralidad e inmediación en la prueba: luces y sombras". Civil Procedure Review, Vol. I, N², 2010; Bordalí, A.; Hunter, I. "Revisión crítica de la oralidad en los juicios en 
también el nuevo procedimiento del trabajo, reformado como se sabe por las leyes $20.087,20.260$ y 20.287 , en la declarada búsqueda de un mejoramiento del funcionamiento de la Justicia del trabajo, especialmente teniendo a la vista las evidentes dificultades del procedimiento anterior para poder resolver adecuadamente y dentro de plazos razonables los conflictos del trabajo ${ }^{2}$.

En consecuencia, la moda de la oralidad (y entiéndase de entrada, que cuando decimos oralidad, decimos también concentración procesal e inmediación judicial efectiva) también ha llegado al procedimiento laboral $^{3}$, donde sin perjuicio de los actos de alegaciones iniciales escritos (convenientemente siguen siendo actos escritos, dando mayor seguridad y fijeza al establecimiento del objeto del proceso), se recoge un modelo bifásico que es predominantemente oral y que se sostiene sobre la base de dos audiencias, la preparatoria y la de juicio ${ }^{4}$. Modelo procesal por audiencias se le llama ${ }^{5}$, y tiene la virtud de asumir una de las principales ventajas asociadas a la oralidad, cual es la concentración procesal, sin necesidad de ceder a los planteamientos más puros o absolutos como los de quienes postularon que sería más acertado y coherente con la idea del modelo oral, especialmente de cara a los mejores resultados de la tutela judicial efectiva, que tras las alegaciones de las partes se procediera en una única audiencia, tras la cual solo restará el fallo ${ }^{6}$.

Chile”. Microjuris, MJCH_MJD2/MJD402, 2010; Palomo, D. "Modelo procesal civil chileno: Conveniencia de articular una nueva regulación sostenida en la oralidad como eje formal facilitador". Revista Gaceta Jurídica, N²91, 2004; PaLomo, D. La oralidad en el proceso civil: el nuevo modelo español. Santiago: Ed. Librotecnia, 2008; Palomo, D. "Las marcas del proceso oral y escrito diseñado en el Proyecto de nuevo CPC". Revista Chilena de Derecho, 2009.

2 A nuestro juicio la vinculación entre ambos procesos de reforma (el civil y el laboral) es evidente. La experiencia acumulada a propósito de la reforma procesal laboral y sus institutos debe ser aprovechada para la reforma procesal civil que debe ver en la nueva Justicia del trabajo una especie de puesta a prueba de una nueva forma de enjuiciamiento sustentada en principios y reglas comunes, más aún cuando entendemos (siguiendo a Montero) que el proceso del trabajo no es más que un proceso civil especial que solo se explica científicamente desde el Derecho procesal. Véase también: Aguilera, R. Proceso laboral y proceso civil: Convergencias y divergencias. Madrid: Ed. Thomson/Civitas, 2004.

3 Véase: Valenzuela, A. "La reforma procesal laboral: de la 'cultura expediente' a la sala de audiencias". Revista Laboral Chilena, N¹70, 2008; TAPIA, F. "El nuevo procedimiento en juicio del trabajo en la Ley 20087/06". Revista de Derecho Social Latinoamérica, №2, Buenos Aires, 2007; Flores, A. "La reforma a la Justicia del Trabajo". Revista Laboral Chilena, 2006.

4 Salvo en el caso de los juicios monitorios que por una definición de celeridad y concentración se determina todo en una sola audiencia, lo que tiene evidentes beneficios para la rápida definición de los procesos, pero evidentes perjuicios para el debido proceso.

5 Véase sobre este punto: Pereira, S. El proceso civil ordinario por audiencias: la experiencia uruguaya en la reforma procesal civil. Montevideo: Ed. Amalio M. Fernández, CEJS - JSCA, 2008.

$6 \quad$ Lo que acontece con la regulación en los juicios del trabajo en algunos países, donde tras la demanda y la contestación, se debe proceder a la realización de una vista donde se concen- 
Postergando en este momento inicial del presente trabajo el abordaje de algunos de los problemas que se identifican en el funcionamiento de la nueva Justicia laboral, se debe reconocer que al menos en el diseńo varios son los méritos que el modelo muestra. Uno de los más importantes, y que se instala de lleno en el tema de este trabajo, dice relación con las importantes reformas introducidas que han incidido en la actividad probatoria, que han tenido por propósito fundamental rescatarla, dándole el protagonismo que realmente requiere, dejando atrás su imagen como una actividad delegada, pobre y fundamentalmente damnificada, como terminaba siéndolo bajo la vigencia del sistema escriturado.

En efecto, el viejo modelo, escriturado, se caracterizaba por negar en los hechos el contacto directo entre el juez, las partes y sus fuentes de prueba. El juez era importante solo al final del trayecto procesal, al momento de dictar sentencia, sobre la base de lo que se había acumulado en el expediente, materializando la idea del juez "lector"7. Era el papel, postergado por la propia estructura del modelo, que se reservaba al juez, el que terminaba siendo prácticamente "invisible" gracias a la cultura de delegación imperante, justificada por el protagonismo total del expediente ${ }^{8}$. Esta situación aparejaba consecuencias ya no solo desde la perspectiva de los tiempos en la respuesta jurisdiccional, convertida en una permanente reivindicación en materia de reformas procesales, sino que en importante medida sacrificaba, a través de la extendida y asumida delegación de funciones, la calidad de los materiales sobre los cuales el juez terminaba pronunciando su sentencia? .

Tempranamente en el proceso de la reforma procesal laboral, específicamente en el documento conocido como Propuesta de bases para la reforma procesal laboral y previsional, generado por el denominado Foro

tran las alegaciones complementarias y la práctica de las distintas pruebas, luego de la cual el asunto litigioso debe quedar pendiente solo de la sentencia. Este modelo más concentrado ha mostrado estar expuesto a una serie de inconvenientes que terminan contaminando al proceso con incidencias y suspensiones, por la falta de preparación del acto, tal como hemos señalado en la nota anterior.

$7 \quad$ Era tal este concepto de delegación que muchas veces los fallos eran hechos por funcionarios del Tribunal y revisados por los jueces, provocando un nivel de mediación que se instalaba en los extramuros de la impartición de justicia. En Chile hubo algunos pequeños escándalos relacionados con estos redactores de sentencias que estaban fuera del sistema e incluso sustituían al juez en su labor esencial en al sistema antiguo.

8 La combinación entre un proceso sostenido básicamente sobre la base de escritos y papeles, formalismos, mediación y delegación, incidencias, práctica de pruebas dispersas inauténticas, tiempos muertos y un juez solo al final del largo trayecto procesal, no se ajustaba a las exigencias que los ciudadanos del siglo XXI plantean. Se imponía la necesidad de la implementación de importantes cambios en la estructura formal del modelo.

9 No es ningún misterio que la calidad de la información que se incorporaba al proceso laboral era bastante pobre, porque el debate sobre la misma era mínimo. Esta pobreza de la información exigía un cambio de magnitud suficiente que transformara sustantivamente la forma del proceso, y la forma en que tanto el juez y las partes se aproximaban a él. 
para la reforma, se diagnosticó con gran claridad que el proceso laboral vigente en ese momento, tanto como consecuencia de la normativa disponible como de su aplicación práctica, conducía "a una producción de prueba deficiente y de mala calidad, intermediada por funcionarios no letrados" y que presentaba "un excesivo ritualismo tanto en su ofrecimiento y rendición, como también en el análisis que se hace respecto de ellas". Este escenario se convertía en un importante obstáculo para la eficiencia del sistema cuando se entiende que el objeto de los procesos debe estar al menos orientado a la resolución de conflictos mediante decisiones justas. Como bien ha dicho Taruffo, "el fondo y la calidad de la decisión adquieren una relevancia extrema, puesto que determinan el núcleo de los propósitos del proceso. Estos propósitos podrían conseguirse o no, pero en todo caso deberían orientar y determinar el funcionamiento de los mecanismos judiciales" 10 .

Pues bien, el diseño procedimental aprobado para los juicios laborales, sostenido como se ha dicho en el modelo procesal por audiencias y la efectiva inmediación judicial que se postula y asegura (a la vez de proscribir la delegación de funciones), ha buscado generar un cambio radical en la comprensión y funcionamiento de la actividad probatoria, con el objetivo esencial de recuperarla en la calidad de los materiales que la misma entrega al juzgador para que pueda pronunciar su sentencia con mejores posibilidades de llegar a un fallo justo, a partir justamente de instalar como un elemento central del nuevo procedimiento laboral el contacto directo, real y temprano entre el juez y las actividades propias de la prueba bajo un esquema de audiencias que debieran permitir generar una prueba pertinente, útil y sobre todo, fiable. La fiabilidad de la prueba es y debe ser el tema esencial de discusión en una reforma como la laboral, y es precisamente en este punto donde no solo existen exiguas normas, sino que además los operadores -jueces y abogados- no ejecutan las labores necesarias para depurar dicha información, con las escasas herramientas que existen en el sistema.

10 Suele olvidarse, en el afán de dejar rápidamente atrás la imagen de una Justicia lenta en su respuesta, que la búsqueda de mayor eficiencia en el proceso (civil, penal, laboral) no debe centrarse exclusivamente en un mejoramiento de los tiempos de la Justicia, sino que junto con ello deben realizarse esfuerzos en que la respuesta jurisdiccional sea de calidad, como bien lo apunta Taruffo. Véase: TARuffo, M. "Oralidad y escritura como factores de eficiencia en el proceso civil”. En: CARpi, F.; Ortells, M. Oralidad y escritura en un proceso civil eficiente. Valencia: Universidad de Valencia, 2008. También una reciente obra: TARuffo, M. Páginas sobre justicia civil. Madrid: Ed. Marcial Pons, 2009. 


\section{2) LA AUDIENCIA PREPARATORIA Y LA AUDIENCIA DE JUICIO DEBEN ESTAR AL SERVICIO DE UNA ACTIVIDAD PROBATORIA DE MAYOR CALIDAD: ALGUNOS PROBLEMAS}

\section{1.) HETEROgÉNEO PROTAgONISMO Y DESEMPEÑOS DE JUECES Y ABOGADOS}

Hemos destacado en el punto anterior la importancia que la figura del juez ha tenido en la revalorización de la actividad probatoria, no solo en el momento de rendición de la prueba sino también en aquella etapa del proceso donde se adoptan decisiones fundamentales respecto de ella. Nos referimos, huelga señalarlo, a la audiencia preparatoria, que se encuentra al servicio, entre otros contenidos previstos en el artículo 453 del Código del Trabajo, de la adecuada preparación de la actividad que se constituye en el eje central de todo proceso, la prueba.

Al momento de plantear la reforma se destacó la tremenda importancia del juez y su ya inicial intervención, como uno de los elementos del modelo que en mejor modo contribuirían al adecuado funcionamiento del mismo. En efecto, el diálogo previo permitiría obtener los mejores frutos, gracias a la implicación temprana del juez con la causa que, de paso, permitiría cambiar rápidamente la imagen del juez solo al final del trayecto procesal por la de uno, desde un inicio, protagonista, profesional, que con diligencia y prudencia dirigiera activamente el debate, para sacar el mayor provecho de la audiencia ${ }^{11} 12$.

De otro lado, el nuevo modelo procesal laboral debía forzar a los abogados a un profundo cambio de hábitos, sobre la base de partir por redescubrir el Juzgado, postergado en la dinámica propia de un sistema escrito donde la delegación de tareas estaba instalada y aceptada. La transparencia propia de la oralidad, que se impone en la nueva forma de enjuiciamiento laboral, debía traducirse naturalmente en el interés de todos los abogados por participar e intervenir adecuadamente de las distintas au-

11 Véase, entre otros textos: Guimaraes, D. "Audiencia preliminar y oralidad en el derecho brasileño". Revista Justicia, N²-4, 2000; De la Oliva, A. "Sobre la Ley 1/2000, de 7 de enero, de Enjuiciamiento Civil: Criterios inspiradores e innovaciones principales”. Revista Tribunales de Justicia, N², 2000; Morello, A. El proceso civil moderno. La Plata: Librería Editora Platense, La Plata, 2001; FAIRÉN, V. La audiencia previa: consideraciones teóricoprácticas. Madrid: Ed. Civitas, 2000; PALOMO, D. "La audiencia previa y el modelo procesal civil oral: consideraciones en torno a una pieza procesal clave". Revista Chilena de Derecho, $\mathrm{N}^{\circ} 2,2005$.

12 Este rol activo se da en mucha mayor medida en los juicios monitorios, donde, sin perjuicio de los problemas de constitucionalidad del debido proceso que pudiere haber, se puede vislumbrar de forma cierta el rol del juez profesional, activo, interviniente y modelador del proceso a su pensamiento. Véase en esto el audio del juicio monitorio Rit 3403-2012, en que la jueza evita fijar puntos de prueba y aplicando sus poderes oficioso requiere la entrega de documentos, para dictar sentencia. 
diencias, comenzando por la audiencia preparatoria en comento que, por sus contenidos y finalidades, impone una seria y temprana preparación del caso. Asimismo, les exigía un alto estándar de preparación y conocimiento que les permitiera defender de manera adecuada los intereses de su parte ${ }^{13}$.

Al respecto cabe preguntarse: ¿Los jueces laborales han estado a la altura de las exigencias referidas? ¿Los abogados han demostrado estar adecuadamente preparados para las mayores exigencias que se derivan del nuevo modelo procesal laboral? Parece obvio que el nuevo modelo de enjuiciamiento oral es uno que debía motivar el interés y responsabilidad de todos los jueces y abogados, no solo por un sincero compromiso con las importantes tareas que a cada uno asigna el legislador, sino en razón de la lógica de absoluta transparencia que se impone con el sistema procesal oral que hace públicos los desempeños profesionales de unos y de otros, exponiéndolos al juicio de otros intervinientes y de la sociedad en general. Sin embargo, en el tiempo que va de aplicación de la reforma, pueden apreciarse notables diferencias en los desempeños de los distintos operadores, tanto entre los jueces como entre los abogados, lo que ha terminado comprometiendo las posibilidades del nuevo sistema y el cabal cumplimiento de las importantes finalidades que se asignaban por el legislador a las audiencias previstas en este proceso ${ }^{14}$.

En lo que dice relación con el juez, y sin pretender desconocer el esfuerzo desplegado por varios jueces que han mostrado comprender perfectamente los mayores deberes y exigencias que apareja la nueva estructura procesal, la verdad es que no siempre se ha podido evidenciar un adecuado y cabal estudio del caso en cuestión, de modo que le permita afrontar los desafíos de la audiencia preparatoria en el rol principal que se le reserva por el legislador ${ }^{15}$.

13 Los jueces, con el correr de la reforma, comienzan a destacar en sus fallos la forma de litigar a los abogados que denotan preparación para los juicios, lo que les facilita mucho el trabajo, por un lado, pero también les permite litigar con mucha transparencia y claridad, lo que sin duda mejora la calidad de la información que se inserta en el proceso.

14 Esta separación entre los objetivos previstos y la realidad se repite en otros lugares. Véase: Muñoz, L. "La inútil ceremonia de la comparecencia previa". Revista Jurídica de Cataluña, №3, 1990; Lluch, X.: "La audiencia previa: Entre el deseo y la realidad", Revista del Poder Judicial, CGPJ, Nº9, 2003.

15 Lo que Andrés de la Oliva denomina el "factor humano" en la Justicia y que explica que un Juzgado, igual que otros en estructura, atribuciones y medios materiales, funciona de un modo muy satisfactorio, junto a otros Juzgados iguales, de peor funcionamiento. Por ello, a su juicio, una análisis adecuado de la situación de la Justicia y su reforma impone al menos atender lo siguiente: " $1{ }^{\circ}$ ) El estado de la Justicia no debiera examinarse, evaluarse y ser objeto de reforma sin otorgar la máxima relevancia al "factor humano" (...); $2^{\circ}$ ) Ese "factor" responde en gran medida al estado de la sociedad; $3^{\circ}$ ) El elemento humano de la Justicia estará a la altura de sus cometidos si no nos conformamos con que solo refleje el ambiente social, sino que procuramos que lo lidere y lo lidere ejemplarmente". Conferencia de clausura de las XX Jornadas Iberoamericanas de Derecho Procesal. Málaga, 27 de octubre de 2006. Véase: 
De hecho, no es poco usual que se constate que los jueces han leído solo justo antes de la realización de la audiencia preparatoria la demanda y la contestación, o peor, que leen la demanda y la contestación en la misma audiencia ${ }^{16}$, con lo cual el dominio del caso en sus aspectos fácticos y jurídicos deja bastante que desear de cara a sacar los mejores frutos de la misma ${ }^{17}$. De más está señalar que esta situación es especialmente problemática cuando se trata de la toma de decisiones en materia de prueba, toda vez que la intervención de un juez laboral responsable y estudioso, por lo tanto, con un acabado conocimiento de los distintos aspectos involucrados en el caso, debe favorecer las posibilidades que a partir del diálogo directo e informado generado en la citada audiencia preparatoria se puedan adoptar decisiones acertadas en lo que dice relación con la prue$\mathrm{ba}^{18}$. Es a ese comportamiento ejemplar ${ }^{19}$ al que debe aspirarse ${ }^{20}$. Es común ver el alivio de los abogados cuando se les asigna un juez estudioso, y que ejemplarmente se ha hecho cargo del juicio, dado que la forma en que se aproxima a los hechos, fija el debate e incluso propone acuerdos es

De la Oliva, A. "El factor humano en la Justicia (hablando claro sobre el tópico "Justicia y Sociedad")". Revista Ius et Praxis, N², 2006.

En el audio de la causa T.81-2012, del Juzgado del Trabajo de Valparaíso, se puede observar a la jueza omitir sin preguntar a las partes la relación somera de los hechos señalados en la demanda, provocando así un problema relevante por cuanto, en el sistema no se le ha dado mucha importancia a esta etapa, siendo que debería ser lo que rigiera el curso de la acción. De todo lo que se dijo es esto lo que se va a discutir, no obstante, y desafortunadamente, esta etapa ha pasado a ser un figura decorativa del sistema.

17 Cabe considerar acá un dato de la realidad de muchos procesos laborales, cual es el hecho que para la audiencia preparatoria existe un juez y para la audiencia de juicio otro (fundamentalmente en Santiago). Ocurre usualmente que el juez de la audiencia preparatoria está más preocupado de lograr una conciliación (incurriendo muchas veces en excesos en donde la proposición se transforma en imposición, con juicios que claramente inhabilitan) que de delimitar la controversia y dirigir el debate probatorio. Al respecto se puede revisar el audio de la causa Rit O-396-2011, ya analizada por nosotros en otro trabajo, donde la sentencia se anula por los excesos del juez en la conciliación. Véase: Palomo, D.; Matamala, P. "Los problemas de los poderes ex officio del juez laboral. Ahora a propósito de la potestad conciliatoria". Revista Ius et Praxis, $\mathrm{N}^{\circ} 1,2012$.

18 Véase especialmente: Berizonce, R. "La oralidad no es para jueces cómodos, sino al revés". Revista Sistemas Judiciales, Ceja, №7, 2004.

19 Son muy pertinentes aquí las palabras del profesor De la Oliva: "No creo en reformas estructurales de mágicos efectos, aunque todos somos capaces de identificar cambios necesarios. Pero los cambios positivos en el factor humano de la Justicia no pueden ser otra cosa que cambios en las personas que protagonizan la Justicia. Y esos cambios solo se producirán (...) si no hay conformismo ante lo negativo y existe, en quienes estamos en mejores condiciones de influir, la determinación indeclinable de promover y exigir razonadamente un comportamiento ejemplar — no común, sino ejemplar — en quienes, de una forma o de otra, hacen la Justicia de cada día”.

20 Pareciera que el debate entre las partes se mira por algunos jueces como una señal de debilidad o de inseguridad más que de la correcta forma de proceder y de determinar el objeto del juicio o excluir pruebas. El sistema oral nos exige mejores estándares de discusión, de debate de ideas dentro del proceso, que nos permita razonablemente lograr un mejor proceso, con más y mejor información, que evite que el juez esté tentado de adquirir el proceso, para determinar su propia teoría del caso y fallar conforme a ella. 
radicalmente distinta que aquel que no lo hace así. La diferencia es abismante. Si no apuntamos a ese comportamiento ejemplar nos quedaremos en una reforma procesal más, que no pasará de las buenas intenciones.

En lo que se vincula con los abogados que intervienen en el marco de un proceso laboral, el panorama es también preocupantemente heterogéneo. Y no nos referimos exclusivamente a la falta de preparación específica en destrezas de litigación oral ${ }^{21}$, mostrando incluso varios abogados una cierta comodidad en la figura principal, activa y protagónica de un juez laboral que a juicio de algunos estaría llamado a suplir las deficiencias en que los profesionales puedan incurrir por su inexperiencia o ineficacia, sino que también a la insuficiente preparación respecto del caso concreto en circunstancias que son los abogados los que mejor deben estar instruidos sobre los aspectos de hecho y de derecho que constituyen el litigio ${ }^{22}$. Cuando eso deja de ser así, y los abogados no cumplen con responsabilidad la representación judicial de sus mandantes, es el sistema el que se resiente, sacrificándose gran parte de las posibilidades que se ponían a disposición de los operadores en la búsqueda de una adecuada delimitación del litigio, una exacta determinación de los hechos a probar, además de una pertinente y útil proposición y admisión de la prueba a $\operatorname{practicar}^{23}$.

21 Llama la atención la escasa o nula penetración que en posteriores reformas procesales, como la reforma a la Justicia de familia y la reforma a la Justicia del trabajo, han tenido todos los aportes normativos y dogmáticos realizados en la materia a propósito de la reforma procesal penal. Los cuidados brindados al tratamiento de la nueva litigación que imponía un nuevo modelo procesal oral penal no se han traspasado a los modelos orales que le han seguido, generando una diferencia notable entre ellos que termina afectando la valoración que se tiene de los mismos. En el sistema procesal laboral, tiene particular importancia el rol subsidiario del juez, por cuanto la norma lo pone como el actor relevante del proceso, y las partes deben estar atentas a evitar perder el control del juicio, con la agravante que en materia laboral exigen pocas y casi ninguna norma expresa de control de la actividad del juez o de las pruebas de refutación que permita, a pesar de la intervención activa del juez, una prueba de calidad.

22 Uno de los elementos dogmáticos de la litigación oral es precisamente que las partes son las que mejor y más saben sobre el caso y no se explica mucho el porqué el juez en ejercicio de sus poderes ex officio pretenda adquirir el proceso para sí. Esta idea de la labor subsidiaria del juez, amplia y sin restricciones, afecta sin duda el proceso en su conjunto.

23 El modelo procesal oral en general y el concreto diseńo de la audiencia preparatoria en particular, debían generar un cambio de hábitos y pautas de trabajo en los abogados, que se verían forzados a comprometerse - de entrada- con sus casos, a través de una mejor y más profunda preparación de los mismos, lo que debía derivar en una mejora de la valoración social que se tiene de su actividad. Con todo, el desempeño de los abogados ha sido, como ya se ha anotado, muy diverso, existiendo no pocos profesionales que aún no entienden las mayores exigencias que impone el nuevo modelo procesal oral. 


\section{2.) LA IMPORTANCIA DE LA AUDIENCIA PREPARATORIA EN LA OB- TENCIÓN DE UNA PRUEBA DE CALIDAD Y FIABLE}

Hemos anotado que la audiencia preparatoria y la audiencia de juicio deben estar al servicio de una actividad probatoria de mayor calidad, entendiendo, como se dijo antes, que un esquema de proceso laboral por audiencias debiera permitir generar una prueba pertinente, útil y sobre todo, fiable, para el caso que fracasen los esfuerzos del juez por poner fin anticipado al litigio ${ }^{24}$.

Ya hemos denunciado en otros lugares la escasa importancia que bajo los modelos escritos se brinda a la actividad probatoria, concebida como una serie de diligencias probatorias tan dispersas como inauténticas, situación potenciada por la ausencia de la figura del juez que se reservaba solo para la dictación de la sentencia. Pues bien, en este escenario, que era el escenario existente antes de la entrada en vigor del nuevo modelo procesal laboral, la actividad de proposición y determinación de la prueba se despachaba sin un conocimiento del asunto que permitiera al juez evaluar la verdadera pertinencia o impertinencia de la prueba propuesta.

El nuevo modelo postula entre sus ejes fundamentales una intervención temprana y efectiva del juez en esta materia, dentro del conjunto de contenidos previstos para la audiencia preparatoria. Pues bien, dos son los contenidos de la audiencia que están al servicio de una actividad probatoria de calidad. El primero de ellos, la determinación del objeto de la controversia, persigue establecer los hechos que resultan controvertidos y que deberán ser acreditados ${ }^{25}$. El segundo contenido, es la proposición y admisión de los medios de prueba que opera sobre la base de lo realizado a propósito del contenido anterior. En definitiva, tras el adecuado abordaje de estos contenidos debían quedar delimitados los hechos sobre los que existiera disconformidad (que deben ser objeto de prueba) y aquellos sobre los que hubiera conformidad y que por esa razón quedaran exentos de la necesidad de prueba ${ }^{26}$.

De lo dicho se desprende que uno de los propósitos del legislador a la hora de recoger la audiencia preparatoria dentro del nuevo esquema de

24 Esfuerzos que como hemos señalado en otros trabajos, incluso se ejercen durante la audiencia de juicio llamando a estas conciliaciones especiales, que lo único que hacen es deslizar la opinión del juez respecto a la sentencia, lo que sumado a la escasa posibilidad de rectificación en las Cortes de estas sentencias, lleva a terminar juicios mediante acuerdos, con la prueba rendida, por el temor de los abogados a las sentencias desfavorables, debido fundamentalmente a la alta dificultad de poder corregir las sentencias a través de los recurso de nulidad, producto del alto formalismo y rigidez al que son sometidos en las Cortes. titud los hechos sobre los cuales exista conformidad y disconformidad.

26 Se habla de la determinación del thema decidendi (de la controversia) y del thema probandi (proposición y admisión de los medios de prueba). 
enjuiciamiento de los procesos laborales, fue evitar los puntos de prueba genéricos, abundantes en los juicios laborales propios del viejo modelo procesal escrito y mediatizado. La pregunta de rigor es si este objetivo se ha cumplido cabalmente.

Si se atiende a lo que ha venido aconteciendo en la práctica la respuesta no es muy alentadora, al menos en la realidad de varios tribunales. En efecto, si bien en un comienzo el propósito legislativo de evitar los puntos de prueba genéricos tan característicos del modelo procesal escriturado que se dejaba atrás, se cumplieron, a poco andar, los estándares de rigurosidad y precisión se han ido relajando, desvirtuando los objetivos asignados a estos contenidos de la audiencia preparatoria a través del resurgimiento de la determinación de hechos generales y no específicos, con el consiguiente peligro que las partes incorporen en estos puntos todo lo que quieran alegar, más allá de las alegaciones planteadas en los escritos de demanda y contestación ${ }^{27}$.

El progresivo relajo de los jueces en la fundamental tarea de determinación de los hechos a probar, a través del retorno a la vieja práctica de la fijación de puntos de prueba genéricos, significa un retroceso importante en un tema que debe ser considerado como uno de los pilares sobre los cuales se puede o no levantar una actividad probatoria de calidad ${ }^{28}$. Esta falta de precisión deriva a que en algunos juicios exista una controversia en la demanda y la contestación de la demanda y otra distinta al momento de rendir la prueba, siendo una dura tarea convencer al juez de la audiencia de juicio (que muchas veces no es el mismo juez de la audiencia preparatoria) en cuanto a que la prueba que se está rindiendo nada tiene que ver con la controversia que efectivamente existe entre las partes ${ }^{29}$. Consecuencia directa de este problema es que la prueba que se rinde en el proceso deja de ser fiable (que era uno de los objetivos de la reforma en

27 Una práctica constante de los abogados más avezados es solicitar la aclaración del juez sobre el contenido del hecho a probar a fin de evitar precisamente una dispersión probatoria que finalmente podría transformarse en una prueba distractora y no enfocada claramente en las teorías del caso de las partes.

28 Nuevamente recordar lo que ocurre usualmente en la práctica, en cuanto que el juez de la audiencia preparatoria muchas veces está más preocupado ( $\mathrm{y}$ a eso destina sus mayores energías) de conciliar, que de delimitar la controversia y dirigir el debate probatorio, lo que deriva en que existe muy poca atención a los hechos a probar que se determinan y a las pruebas que se ofrecen.

29 Claramente hay acá un problema que cabe denunciar, más si frente al ofrecimiento de las pruebas por las partes, corresponde al tribunal declarar la pertinencia o impertinencia de las mismas. En la lógica del nuevo modelo procesal el tribunal no debiera operar mecánicamente admitiendo cualquier medio de prueba que las partes postulen en apoyo a sus defensas, sino solo aquellos que estime pertinentes, sin dejar de lado las teorías del caso de cada parte. Lamentablemente muchas veces algunos jueces olvidan este hecho esencial, afectando severamente la igualdad de armas, la contradicción, y el derecho a la debida defensa. 
materia probatoria), ya que se encuentra groseramente contaminada con otros hechos ${ }^{30}$.

\section{3.) LA AUDIENCIA DE JUICIO COMO INSTRUMENTO DE RESCATE DE LA PRUEBA ENTENDIDA COMO EL EJE FUNDAMENTAL SOBRE EL CUAL GIRA EL PROCESO}

La delegación y desconcentración procesales propias del modelo escriturado había terminado afectando la seriedad de la actividad de la práctica probatoria (en especial de las pruebas personales) y de la propia dignidad de la tarea judicial. En efecto, un modelo como el que existía fomentaba la existencia de un juez ajeno a los menesteres de la actividad probatoria, recluyéndose en la tarea exclusiva de sentenciar sobre la base de unas actas que recogidas por un funcionario daban cuenta de las pruebas rendidas en el proceso. La prueba estaba damnificada, inmersa en una dinámica de desprestigio.

La prueba ahora se practica en la audiencia de juicio, en unidad de acto, con activa participación del juez y publicidad, y desahogada de la serie de formalismos que le ataban bajo el modelo de enjuiciamiento precedente. Eso busca constituir un giro copernicano en la manera de entender la importancia de la prueba en el marco de un proceso, cerrando definitivamente la puerta a delegaciones, y poniendo al juez en contacto directo y frontal con las partes y sus medios de prueba, escuchando y viendo en persona y sin intermediarios la declaración de las mismas, de los testigos, y las explicaciones de los peritos, todo ello en unidad de acto, tras lo cual se impone dictar sentencia en breve plazo al mismo juez que haya recibido directamente las pruebas rendidas en la causa ${ }^{31}$.

Esto que parece de una obviedad evidente como el personaje de Quevedo, constituye una circunstancia esencial que a través de la mala práctica de los hechos de prueba genéricos queda desterrada de la buena práctica judicial. Si las partes alegaron circunstancias determinadas en la demanda y contestación, cuyos hechos esenciales además se deben reflejar en la relación somera de hechos, no se avizora motivo alguno para poder determinar hechos en forma genérica, sino que muy por el contrario, la determinación de los mismos, ya debería estar dada por la relación determinada que el mismo juez hace. El problema como hemos ya indicado, se agrava cuando esta relación somera de hechos constituye una lectura rápida de los escritos fundamentales del pleito, y no una relación de los hechos esenciales, lo que concatenado con la desidia de las partes de dejar que el juez determine en forma genérica los hechos a probar, finalmente se vuelve, oralmente, a vicios del pasado que se quisieron evitar con la reforma. La parte diligente ha encontrado solución para esto, y es ir reponiendo, o al menos mencionando al juez hechos relevantes que se entienden incorporados en este hecho abierto. Esta práctica "salva los papeles", pero no es un proceder esperable en un modelo de juicio por audiencias, donde las partes deben señalar determinadamente sus pretensiones.

31 Véase: Chiovenda, G. "L'oralitá e la prova". Rivista di Diritto Processuale Civile, Vol. I, 1924; Cappelletti, M. La oralidad y las pruebas en el proceso civil. Buenos Aires: EJEA, 1972. Entre nosotros: Pérez-Ragone, A.; Palomo. D. "Oralidad y prueba: comparación 
Con todo, la renovada dinámica de la práctica probatoria de los procesos laborales, que se recoge fundamentalmente en el artículo 454 del Código del Trabajo, no ha estado exenta de algunos problemas de funcionamiento tanto en lo que liga con la prueba documental como respecto de lo que acontece con las llamadas pruebas personales, en especial la testimonial y confesional.

En lo que liga con el primero de los medios de prueba aludidos, se sabe que se establece que la prueba documental debe ofrecerse y presentarse en la audiencia preparatoria, sin perjuicio de que se impugne en ella o en la audiencia de juicio. Se hará en la audiencia preparatoria cuando su impropiedad sea obvia, pero existen documentos cuya parte a incorporar se desconoce en ese momento, por lo que no se sabe si se puede impugnar o no. El problema se ha suscitado con algunos pocos jueces, en contra de la explícita alternativa prevista por el legislador, han señalado que se debe impugnar en la audiencia preparatoria y no en la de juicio, señalando que la parte no se ha reservado el derecho a impugnar en esta última audiencia. Esto que parece lógico, dista de lo que señala la ley, que entrega a las partes esa posibilidad refutación ${ }^{32}$.

La incorporación procesal de la prueba documental se materializa en la audiencia de juicio. Pues bien, se ha instalado una práctica de incorporación procesal de esta prueba muy negativa, consistente en que solo se leen los encabezados de los documentos y nada más, lo que evidentemente no puede alcanzar para decir que hay una lectura extractada del documento y que ha existido verdadera incorporación procesal del mismo $^{33}$. Los jueces han venido consolidando esta práctica, aceptándola los abogados, lo que es censurable, más cuando esta incorporación en la audiencia de juicio se debe dar en términos de que la parte dé fundamentos del contenido probatorio del documento, en cuanto a los efectos que de ella se producirán en respaldo de las afirmaciones fácticas contenidas en la demanda o en la contestación. El problema es que cuando se da esta situación, el juez no ha escuchado la parte del documento que se quiere

y análisis crítico de las experiencias reformadoras del proceso civil en Alemania y España”. Revista de Derecho Pontificia Universidad Católica de Chile, $\mathrm{N}^{\circ} 1,2009$.

32 Esto vulnera los derechos de la parte afectada, porque normalmente en la audiencia preparatoria será la primera vez que se conoce un documento y solo a partir de allí se podrá averiguar sobre su veracidad o validez, por lo que la eventual impugnación se hará en la audiencia de juicio. Los jueces no debieran plantear este problema si lo que se busca es depurar la prueba que se rinde.

33 Puede verse el audio de la audiencia de juicio de la causa Rit O-2450-2012, donde la jueza no solamente solicita que se lean los títulos de los documentos, sino que además, "recomienda" a una de las partes a desistirse de la prueba testimonial, violando el debido proceso en forma abierta, y prácticamente informando a las partes su decisión sobre el caso. 
incorporar y, en consecuencia, no va a poder saber de qué le están hablando, comprometiendo su mérito probatorio ${ }^{34}$.

Por su parte, la denominada prueba confesional también ha generado algunos problemas y algunas dudas. Como se sabe, este medio de prueba implica la citación del demandante o demandado con el fin de que preste declaración en una diligencia probatoria que tras la reforma ha dejado atrás el absoluto encorsetamiento y rigidez formal que le caracterizaba y del cual eran símbolos los pliegos de posiciones ${ }^{35}$. Hoy, la diligencia se realiza en forma verbal, con mayores grados de libertad y flexibilidad y con la presencia efectiva del juez, siendo interrogado el citado sobre los hechos discutidos del juicio. El tribunal puede formular preguntas, rechazarlas y ordenar que la parte precise o aclare sus dichos.

En el terreno de la espontaneidad que se pretende en el interrogatorio de la parte, la práctica de esta prueba ha evidenciado la necesidad de que el abogado de la contraria y el propio juez estén muy atentos al desarrollo del interrogatorio para evitar que la diligencia probatoria se transforme en una actuación donde las respuestas de la parte tengan poco o nada de espontáneas. De hecho, no es poco común que dada la distribución de los lugares dentro de la sala de audiencia el interrogatorio de parte realizado por un abogado permita a la parte que está siendo objeto de la serie de preguntas "consultar" a su abogado antes de responder a través de un cruce de miradas por las que pide una confirmación o negación en relación a lo que se le está interrogando.

Las dudas se han presentado cuando la parte no es citada por la contraria, sino que su declaración se ofrece por ella misma. Bajo el sistema de libertad probatoria que se recoge en el Código del Trabajo debiera admitirse la incorporación al proceso de toda fuente probatoria que, siendo pertinente, contribuya a acreditar la efectividad de las afirmaciones fácticas planteadas por las partes en sus escritos de alegaciones, más aún si se ha dejado atrás la concepción negocial de la absolución de posiciones, entendida más como declaración de voluntad que como una declaración de conocimiento ${ }^{36}$. Sin embargo, no ha sido así, y los tribunales no lo

34 Normalmente los testigos se pronuncian sobre los documentos o su contenido y alcance, por lo que es evidente que es relevante que estos documentos tengan una importancia sustantiva en la defensa de las partes, y en la forma en que las partes quieren presentar su caso frente al juez.

35 Lo que ha buscado el legislador es superar la excesiva rigidez de la absolución de posiciones, ejemplificada en la existencia del interrogatorio formal contenido en los pliegos de posiciones, buscando incorporar mayor agilidad, espontaneidad y flexibilidad en la práctica de la prueba.

36 Entendemos que lo que ha buscado el legislador es superar la rigidez de la absolución de posiciones incorporando mayor flexibilidad, característica fundamental si con esta prueba no solo se persigue el reconocimiento de unos hechos perjudiciales para la parte que declara, sino que recoge también la finalidad de información sobre los hechos y circunstancias sobre los que el declarante tenga noticia y guarden relación con el objeto del juicio. 
han autorizado. Ante este escenario, y entendiéndose como una fuente de información privilegiada, los abogados han intentado incorporar estas declaraciones por la vía de la denominada prueba innominada, pero no es una fórmula que haya prosperado demasiado en el foro. Solo algunos tribunales lo han admitido, y han aplicado las normas de la prueba testimonial para la declaración de estas partes. Pero lo peor se ha dado en los juicios por reclamaciones de multas, donde no se da lugar a la citación de los inspectores del trabajo que han dictado las resoluciones que se recurren, por las más exóticas razones, que emergen de las convicciones ideológicas personales de los jueces y se alejan sustantivamente del debido proceso $^{37}$.

Tratándose de la prueba testimonial, las ventajas que puede ofrecer y de hecho ofrece la opción por un modelo procesal oral son también, fundamentalmente, la mayor flexibilidad y espontaneidad en la diligencia probatoria. Se ha buscado superar, en el contexto de un nuevo modelo procesal oral, la tradicional desconfianza del legislador hacia ella, cuyas consecuencias derivaron en su desvalorización y desprestigio en la práctica judicial. El nuevo esquema de enjuiciamiento permite la revitalización de la prueba testimonial fundamentalmente porque los jueces ya no pueden desentenderse de ella a través de la delegación ${ }^{38}$.

Se opta, en consecuencia, por establecer un interrogatorio oral, libre y directo, que pone en relación frontal al juez, los abogados y los testigos, de modo tal de garantizar la flexibilidad en las preguntas y la espontaneidad en las respuestas. En definitiva, se persigue la integridad de una declaración no preparada que permita incorporar una prueba testimonial fiable al proceso. Todo ello por la vía de la técnica del interrogatorio cruzado que, como se sabe, ofrece unas determinadas posibilidades de preguntas en el llamado interrogatorio directo y otras, más amplias, en el denominado contraexamen ${ }^{39}$. Si en el desarrollo del interrogatorio el juez

37 En la causa Rit I-1-2012 de San Miguel, la juez señala que no es necesario citar a absolver posiciones al funcionario público que dictó la resolución que se recurre por cuanto él ha hablado ya por la resolución que se impugna. Frente al argumento que se le indica que teniendo en cuenta ello, entonces el representante de la empresa tampoco podría ser llamado a absolver porque él "hablaría" en su demanda o contestación, el argumento en el audio, es que ese caso es distinto. Este nivel de discusión jurídica, nos aleja de los fines de la reforma y de la aspiración que las partes tengan libertad de refutación de pruebas como ya lo señalaron incluso en el Acta Constitucional No 3.

38 La ausencia del juez se había transformado en el verdadero talón de Aquiles de la prueba testimonial. Al no estar presente en el acto y reduciéndose su contacto con la prueba a las actas levantadas por un funcionario, la actuación probatoria perdía casi toda su eficacia y utilidad. A las razones de esta ausencia en un modelo escriturado ya nos hemos referido en otros lugares.

39 Sabido es que en la técnica del cross examination mientras el abogado que ha presentado al testigo no puede hacerle preguntas sugestivas, realizar valoraciones o calificaciones en las preguntas, o sacar a relucir su credibilidad, el abogado de la contraparte sí que está habilitado para todo ello, siempre bajo el control del juez. Se distingue, en consecuencia, entre el 
experimenta percepciones que lo llevan a desconfiar seriamente de la versión entregada por el testigo, debiera requerir inmediatamente precisiones y aclaraciones al declarante, con la finalidad específica de conceder o negar credibilidad a la versión entregada ${ }^{40}$.

Los problemas en relación con la prueba testimonial han venido principalmente por las dificultades que han evidenciado los jueces para entender la rapidez propia que debe poseer un interrogatorio oral, libre y cruzado. Se aprecia lentitud en lo que liga con las objeciones que se plantean a las preguntas, tanto en el interrogatorio directo como en el contraexamen, ya que los jueces confieren traslado de las mismas a la contraria, posibilitando que las partes argumenten "entregando" la respuesta al testigo $^{41}$, comprometiendo con ello la fiabilidad y credibilidad probatoria que se ha buscado recuperar en el nuevo modelo ${ }^{42}$.

Se ha intentado también usar la vía de acercarse los abogados al estrado, para de ese modo evitar el problema señalado, que termina con que la deposición del testigo resulta ser conducida por el abogado que lo presenta. Sin embargo, muy pocos jueces lo han aceptado, lo que es especialmente problemático si se atiende a la finalidad que persiguen las objeciones, cual es, que la información que se extraiga de testigos y otras fuentes de prueba sea de alta calidad, y por lo tanto, confiable.

Finalmente, un breve pero importante comentario sobre las consecuencias que debiera aparejar una convicción, cual es, que nadie está en mejor posición que las partes para extraer la información relevante y ponerla a disposición del tribunal, tanto para evidenciar su credibilidad como para mostrar sus defectos. Así por ejemplo, tratándose de la prueba testimonial, siempre debiera privilegiarse el interrogatorio directo por las partes para luego pasar al interrogatorio del juez. Autorizar al juez actuar en primer lugar es imponerle un papel impropio de litigante ${ }^{43}$. Asimismo, que el juez interrogue con amplias libertades y escasos límites, también

direct examination y el cross examination, este último al cual se le reconoce una función eminentemente crítica.

40 Acá podemos disentir de la epifanía o iluminación como diría Perfecto Andrés Ibáñez, que supuestamente puede llevar al juez a creer o no determinada declaración, pero sin duda que, en la práctica, exámenes y contraexámenes de testigos bien realizados resultan ser de gran utilidad para el juez y las partes, sobre todo si estas cubren las aristas en que el juez tenga intención de escudrińar, para evitar lo que hemos llamado la adquisición del proceso por parte del juez.

41 Véase el interrogatorio directo de los testigos de la parte demandada y demandante en audio de juicio del Primer Juzgado del Trabajo de Santiago O-2416-2012, donde la diferencia entre ambos interrogatorios es evidente, tanto que incluso la Jueza en forma correcta le llama la atención al abogado de la parte demandante para que efectúe las preguntas de forma correcta.

42 Los testigos deben declarar sobre su conocimiento de los hechos, no influenciados por quien los presenta.

43 Conocida es la postura de algunos jueces, que son ellos los encargados de interrogar en primer lugar dado el orden que señala la ley. Véase audio de O-2923-2012 del Primer Juzgado 
afecta a las partes y su forma de plantear el proceso, lo que no debe tolerarse si no se quiere transformar un verdadero proceso en un mero procedimiento ${ }^{44}$.

\section{3) El CONTROVERTIDO PAPEL DEL JUEZ DEL TRABAJO EN LA DisPOSI- CIÓN DE DILIGENCIAS PROBATORIAS DE OFICIO}

A propósito del cambio, desde un sistema escriturado con un juez ausente hacia uno oral con inmediación efectiva en que se autoriza al juzgador para decretar de oficio en la audiencia preparatoria las diligencias probatorias que estime conducentes, las que deberán llevarse a cabo en la audiencia de juicio, podemos hacer algunos apuntes.

Para algunos, la abreviación de la duración de los juicios, la opción por la oralidad y el reforzamiento de los poderes del juez forman parte de una nueva concepción de la justicia, denominada justicia social, que busca acercar la justicia a las clases más desposeídas. Es en este contexto de mayor implicación estatal en el proceso, que cabe examinar la amplia autorización a los jueces para disponer prueba oficiosa que, a propósito de este giro ideológico adquieren un mucho mayor protagonismo tanto en lo que dice relación con las facultades procesales de dirección ${ }^{45}$, como con las facultades materiales (que afectan el contenido de la decisión final) desde donde se postula un incremento de los poderes probatorios del tribunal, a través de los cuales se persigue la obtención de una sentencia justa sustentada en el establecimiento de la verdad de los hechos ${ }^{46}$.

Entre las manifestaciones de estos poderes materiales de dirección, encontramos la potestad del juez de inadmitir prueba ofrecida por las partes por considerarla inconducente, impertinente o innecesaria para la resolución del asunto, la atribución del juez de impedir la rendición de prueba antes admitida que a su juicio constituyan una inútil reiteración sobre los mismos hechos (artículo 454 n³ y no5 del Código del

del Trabajo de Santiago, lo que sin duda alguna vulnera el principio esencial del debido proceso y constituye el epítome de la adquisición del proceso por parte del juez. juez en el interrogatorio de testigos en el juicio laboral oral y sus necesarios límites". Revista Ius et Praxis, $\mathrm{N}^{\circ} 2,2011$.

45 El tribunal, reclamada su intervención en forma legal, actuará de oficio, adoptará las medidas tendientes a evitar la paralización del proceso y su prolongación indebida, corregirá de oficio los errores que observe en la tramitación del proceso y adoptará las medidas que tiendan a evitar la nulidad del procedimiento.

46 En el terreno de los principios se puede estar más o menos de acuerdo con los sistemas que entregan toda la responsabilidad del proceso a las partes o, por el contrario, que se la entregan al juez, pero la realidad nos muestra que no existen sistemas puros en la materia. Los sistemas procesales de la realidad muestran una combinación de roles y facultades entre jueces y partes. 
Trabajo $)^{47}$ y el poder de decretar prueba oficiosa. A este último nos queremos referir especialmente.

Algunas observaciones cabe señalar respecto a estos poderes oficiosos del juez laboral en materia de prueba, sin que se nos diga que avalamos la injusticia, la mentira o la dilación. Se trata simplemente que el juez, por buscar el valor de la justicia (que siempre ha de procurar), no está autorizado a vaciar de contenido la noción misma de proceso. Además, como se ha planteado acertadamente, si la sentencia será justa, o más justa, por la correcta determinación de los hechos, ¿cuál sería la razón por la que un tercero ajeno a los hechos (el juez) debiera ser el mayor responsable de su determinación?

Sin entrar acá en la profundidad del debate de las facultades de los jueces en materia probatoria ${ }^{48}$, cabe realizar una consideración general a las variadas dificultades que plantea el proceso de cara al establecimiento de la verdad. Ya lo planteaba Carnelutti al descartar que el proceso sea una máquina con la cual, introducida por una parte la demanda de justicia, obtengan por otra la respuesta perfecta ${ }^{49}$. Por eso, ante todo corresponde usar el término verdad con mucho cuidado, entendiendo de entrada que la actividad de la prueba es una actividad verificadora, no investigadora. El proceso, las limitaciones provenientes del principio dispositivo (que a pesar de lo que sostengan algunos no se ha derogado con

En la práctica se han generado tensiones con el derecho a la prueba de las partes.

Véase al respecto: Alvarado, A. Garantismo procesal contra actuación judicial de oficio. Valencia: Ed. Tirant lo Blanch, 2005; Alvarado, A. La prueba judicial: reflexiones sobre la confirmación procesal. Santiago: Ed. Librotecnia, 2009; CiprianI, F. Stato di diritto e garanzie processuali: atti delle II Giornate internazioni di Dirito processuale civile. Napoli: Edizioni Scientifiche Italiane, 2008; PARRA, J. Racionalidad e ideología en las pruebas de oficio. Bogotá: Ed. Temis, 2004; Barbosa, J. "La significación social de las reformas procesales". Revista de Processo, 131, 2006; ChIARLONI, S. "Reflexiones microcomparativas sobre ideologías procesales y comprobación de la verdad”. Revista Internauta de Práctica Jurídica, N²4, 2009; DInamarco, C. La instrumentalidad del proceso. Lima: Ed. Communitas, Traducción de José Monroy P., 2009; Luco, N. “¿De vuelta al sistema inquisitivo? En: Leturia, F. (Ed.). Justicia civil y comercial: una reforma ¿cercana? Santiago: P. Universidad Católica de Chile, U. Diego Portales y U. del País Vasco, 2011; Montero, J. Sobre la imparcialidad del juez y la incompatibilidad de funciones procesales. Valencia: Ed. Tirant lo Blanch, 1999; Peyrano, J. "El perfil deseable del juez civil del siglo XXI”. En: Silva, J.; García, J.; Leturia, F. (Coords.). Justicia civil y comercial: una reforma pendiente. Bases para el diseño de la reforma procesal civil. Santiago: P. Universidad Católica de Chile, Universidad Autónoma de Madrid, Instituto Libertad y Desarrollo, 2006; Picó, J. "El Derecho procesal entre el garantismo y la eficacia: un debate mal planteado". Revista Iberoamericana de Derecho Procesal, N4, 2004; Vescovi, E. "Los poderes probatorios del juez civil en los nuevos sistemas procesales". En: Studi in onore di Vittorio Denti. Padova: Ed. Cedam, Vol. II, 1994; Ramírez, D. "La oralidad y su relación con los poderes de instrucción que tiene el juez en el proceso". En: TARuffo, M.; Ramírez, D. (Dir.). Conocimiento, prueba, pretensión y oralidad. Lima: Ara Editores, 2009; TARuffo, M. "Investigación judicial y producción de prueba por las partes". Revista de Derecho Universidad Austral de Chile, 2003; Palomo, D. "Proceso civil oral ¿Qué modelo de juez requiere?". Revista de Derecho Universidad Austral de Chile, Nº1, 2005.

Véase: Carnelutti, F. Lezioni di Diritto Processuale Civile. Padova: Cedam, III, 1921. 
la reforma) y las demás restricciones legales y constitucionales, permiten acceder a una verdad que muchas veces poca relación tendrá con la verdad histórica.

En este terreno resulta sencillo caer en la caricatura del juez superhéroe, asistencial, con reforzado protagonismo y amplios poderes de dirección, entre ellos, los comentados poderes oficiosos en materia de prueba. Como consecuencia, termina comprometiendo la imparcialidad del tribunal, la igualdad de armas, la contradicción, el debido proceso en general, dejando el campo abierto a la arbitrariedad, además de debilitar la calidad y fiabilidad de la información que se incorpora al juicio, configurando un escenario que no puede ser considerado positivo. Este riesgo se ha materializado a propósito de la reforma procesal laboral.

Se instala la idea de que un modelo de justicia que hace justa la decisión por provenir de un proceso respetuoso de ciertas reglas elementales ya no es compatible con el objetivo de implementar un "verdadero" cambio en la Justicia. Se impone el dogma maniqueo que ese modelo representa todo lo malo e ineficiente y que debe ser reemplazado por un modelo de Justicia "de la decisión" que brinde protagonismo casi excluyente a la meta, esto es, a la sentencia justa, lo único que verdaderamente importa.

Con la reforma, y de la mano de la apuesta por un modelo oral, empieza a ser parte del discurso oficial que de la crisis de la Justicia no se sale sin aumentar muchísimo las potestades oficiosas de los jueces. Empieza a ser parte del discurso que los jueces, al representar al Estado en el proceso, tienen el deber de eficacia y de justicia en las personas, por lo que su labor no puede ser detenida ni obstaculizada por cuestiones técnicas o sutilezas procesales garantistas que posterguen el derecho a la tutela judicial efectiva. Si para lograrlo, había que regular las garantías procesales a la baja, como de hecho acontece, constituiría el precio a pagar por un verdadero cambio.

Bajo este modelo, se reproduce muy fácilmente la idea que las garantías procesales, las partes, sus abogados constituyen un obstáculo para la búsqueda de la verdad, la Justicia, y para el logro de una respuesta jurisdiccional efectiva y oportuna para las personas. Los objetivos a conseguir justificaban y exigían confiar en los jueces, que utilizando estos reforzadísimos poderes estarían en condiciones de acceder a los mismos. Se postula una desbordada confianza en la creatividad, buen criterio y libertad de los jueces, sin prácticamente límites, lo que ha aparejado perniciosas consecuencias en el concreto desempeńo de los jueces en la realidad de los procedimientos, lo que no escapa a nadie, especialmente a los abogados que intentan ejercer la profesión en esta área.

En efecto, en el entendido que están cumpliendo con el encargo recibido en la reforma, los jueces han hecho uso de sus potestades oficiosas 
y muchas veces esta conducta ha significado un serio retroceso para las garantías de las partes que se han visto paralizadas y derechamente postergadas por la actuación protagonista del juez que se termina apropiando del proceso, sin límites y sin contrapesos. En otras palabras, la reforma ha permitido jueces que en el afán de cumplir los objetivos encargados se comportan como partes (asumiendo tareas que a ellas les corresponden), pero con mayores poderes, sacrificando elementos esenciales de todo proceso, sacrificando la calidad y fiabilidad de la información que se incorpora al proceso ${ }^{50}$ y sacrificando también la imagen de la Justicia por la falta de la seriedad objetiva que requiere el ejercicio de la función jurisdiccional por las conductas de jueces que en no pocas ocasiones dejan de comportarse como verdaderos jueces para asumir un protagonismo que llega a ser sustitutivo de las partes y sus abogados, que terminan paralizados.

Pues bien, ya se han alzado voces entre los propios laboralistas criticando los excesos a que puede dar lugar este nuevo modelo de juez laboral ${ }^{51}$. Y eso, si se tiene a la vista lo que se ha venido predicando uniformemente desde dicha disciplina, es bastante. Dicho claramente, la línea que divide al juez "director" del juez "dictador" y "autoritario" parece peligrosamente tenue en muchos casos que muestra la realidad de nuestros tribunales del trabajo, donde los problemas comienzan con los excesos que ocurren a propósito de la tarea conciliatoria, con juicios que son claramente inhabilitantes y conductas derechamente censurables ${ }^{52}$, y se completan con la posibilidad de disposición oficiosa de medios de prueba en un modelo que, conforme se desprende de la propia normativa, no asegura garantías mínimas a las partes.

Reconocida legalmente esta potestad a los jueces laborales es necesario interpretarla del modo menos dańino para los principios ya anota$\operatorname{dos}^{53}$. Así, de acuerdo a lo que se ha venido postulando por la doctrina,

Véase: Duce, M.; Marín, F.; Riego, C. "Reforma a los procesos civiles orales: consideraciones desde el debido proceso y calidad de la información". En: Cabezón, A. (Coord.). Justicia civil: perspectivas para una reforma en América Latina. Santiago: Ceja - Jsca, 2008.

51 Véase: Palavecino, C. "El retorno del inquisidor. Las potestades judiciales en materia probatoria en el procedimiento laboral chileno". Revista Laboral Chilena, $N^{\circ} 173$, 2009; Palavecino, C. El retorno del inquisidor: critica a la iniciativa probatoria judicial. Asunción: Ed. La Ley Paraguaya, Colección Brevarios procesales garantistas, 2011.

52 Como la costumbre de algunos jueces de apagar el audio al momento de profundizar en su intervención conciliatoria, en demasiadas ocasiones mucho más cercana a una imposición que a una proposición a una de las partes. Véase: Palomo, D.; Matamala, P. "Los problemas de los poderes ex officio del juez laboral. Ahora a propósito de la potestad conciliatoria”. Revista Ius et Praxis, N1, 2012.

53 La asignación de reforzados poderes en los jueces está presente en muchos procedimientos, es una realidad de la cual hay que hacerse cargo, guste más o menos, se comparta o no la creencia que se está frente a la fórmula mágica que pondrá solución a la crisis de la justicia. En consecuencia, con mayor realismo, se hace necesario concentrar los esfuerzos en definir y determinar los límites para las potestades judiciales ex officio. 
esta potestad debiera limitarse al menos en estos aspectos ${ }^{54}$ : i) que la prueba practicada por el juez se limite a los hechos controvertidos o discutidos por las partes; ii) la necesidad de que consten en el proceso las fuentes de prueba sobre las cuales tendrá lugar la actividad probatoria del juez, y iii) el respeto, en todo momento, del principio de contradicción y el derecho de defensa que cualquier litigante posee en el desarrollo de la prueba, permitiéndole proponer nuevas pruebas y, evidentemente, participar de toda la actividad probatoria. El fundamento de estos límites radica en entender que la potestad probatoria no puede nunca llegar a ser sustitutiva de la actividad de las partes, sino solo marginal y complementaria, esto es, solamente utilizada cuando no resulta suficiente la propuesta probatoria de ellas.

A partir de este reconocimiento, y para no vulnerar el derecho de defensa de las partes, se ha postulado que el juez que decreta prueba de oficio debe, respetando el marco fáctico del proceso ${ }^{55}$, dar la oportunidad a la partes para controvertir la pertinencia o relevancia de la prueba que se intenta introducir de oficio, para participar en su realización, para producir contraprueba y para discutir acerca de la eficacia de la prueba de oficio antes de su decisión. Lo que es lo mismo a señalar que a mayores potestades oficiosas del juez, como acontece en el proceso laboral, mayor reforzamiento de la contradicción y de los controles asegurados a las partes 5657 .

No existe en la norma del artículo 453.9 del Código del Trabajo ninguna limitación como las recién anotadas, por lo que se vislumbra un riesgo (que se ha materializado) donde el juez tiene su propia teoría del caso, que decreta o puede decretar de oficio pruebas, con el consiguiente riesgo que el juicio deje de ser de las partes y pase a ser del juez. El juez cuenta con poderes probatorios importantes y puede terminar dejando fuera de combate a partes bien armadas con este tipo de diligencias (así

54 Véase: Picó, J. "Los principios constitucionales rectores del proceso civil en Espańa: los principios referentes al objeto del proceso, su dirección y desarrollo formal”. Revista Advocatus, $\mathrm{N}^{\circ} 10,2004$.

55 Se ha consolidado incluso entre quienes son partidarios de los mayores poderes probatorios de los jueces la interpretación que sostiene que estas facultades se limitan a los hechos alegados por las partes. En consecuencia, se debe respetar el hecho de que el material fáctico del proceso lo proporcionan únicamente las partes. En este sentido, el juez no podría invocar en sustento de su decisión cuestiones de hecho no alegadas por las partes en sus escritos de alegaciones, al hallarse limitada su iniciativa probatoria a los hechos alegados y controvertidos por las partes.

56 Esto lamentablemente no ocurre en nuestro sistema, por cuanto el juez decreta su prueba al final y las partes pueden controvertir, pero difícilmente se aceptará una prueba que se oponga a la decretada por el juez.

57 Excelente ejercicio de bilateralidad de audiencia en la dictación de prueba de oficio y omisión de prueba de las partes en la causa Rit I-303-2012 del Primer Juzgado de Letras del Trabajo de Santiago. 
como también con las declaraciones de pertinencia, conducencia o necesariedad de la prueba).

Pues bien, algunos jueces han realizado un ejercicio moderado y adecuado de estos poderes, sin pasar por encima de la imparcialidad, ni la igualdad de armas, la contradicción y el derecho de defensa de las partes. Otros en cambio, han mostrado una actuación oficiosa que evidentemente excede los márgenes de la prudencia mostrando un juez que impone su propia teoría del caso que puede coincidir con la de una de las partes o puede sustituir la teoría del caso sustentada por las partes. Esta cuestión aparece particularmente problemática si se atiende a que en varias oportunidades la prueba de oficio dispuesta por el juez recogerá su propia teoría del caso y, como ya lo hemos dicho, no siempre el juez que la decreta en la audiencia preparatoria será el mismo juez de la audiencia de juicio.

Luego de lo expresado, volviendo al objetivo principal que -se dicejustifica los poderes oficiosos del juez en materia de disposición de pruebas ¿en qué situación queda la determinación de la verdad en el proceso laboral? Es solo una aspiración a la cual no puede comprometerse ni el legislador ni menos el juez. Al primero lo que sí le corresponde es diseñar un procedimiento que imponga el efectivo contacto directo del juez con la causa, las partes y sus medios de prueba, enterándose, de primera fuente, de los distintos extremos del asunto. Al segundo lo que le corresponde es conducir el proceso a su fin, con pleno respeto de los principios fundamentales sin los cuales pasa a ser un mero simulacro, tales como la imparcialidad, la igualdad de las partes, la contradicción y el derecho de defensa, conjugándolo con las mayores posibilidades de obtener una verdad procesal de superior calidad a través de la efectiva intervención del juez en la práctica de la prueba.

La apuesta por un modelo procesal oral importa, por asumirse una más razonable estructura procesal, un temprano contacto del juez con la causa, las partes y los abogados. Importa también dejar a tras una Justicia sin rostro, lejana y aparentemente poco preocupada por los asuntos que le tocaba resolver. Sobre todo, importa recuperar la actividad probatoria, con la expulsión de la delegación tan extendida y tolerada en un modelo procesal escriturado. Pero correspondería que a estas alturas se dejara atrás el entendimiento de la eficiencia en una sola dirección, atendiendo exclusivamente a lo que impone la Justicia de las estadísticas y la consideración del factor tiempo ${ }^{58}$. Por lo tanto, el tránsito hacia la oralidad en los juicios (se incluye acá la reforma procesal laboral) no debió importar nunca la asunción de una fórmula desbordada que termine reforzando, sin lí-

Este es un escenario que no solo muestra conductas reñidas con la debida imparcialidad, con el derecho de defensa y el principio de contradicción, sino que compromete la fiabilidad de la información que se incorpora al proceso, en un contexto que privilegia desequilibradamente la celeridad de la respuesta por sobre su calidad. 
mites claros ni contrapesos bien definidos, las potestades de los jueces 59 , afectando garantías elementales previstas incluso a nivel constitucional ${ }^{60}$.

Cuando así lo ha dispuesto el legislador, equivocadamente, cabe exigir una aplicación prudente y razonable de estas potestades por parte de los jueces, velando por asegurar unas garantías procesales mínimas que impidan que el caso deje de ser de las partes y pase a ser exclusivamente del juez, con todas las consecuencias dañosas que pueden asociarse a ese resultado. Y allí donde no exista la prudencia esperable de un juez por el solo hecho de ser juez, cabe esperar abogados que no se paralicen y sean capaces de controlar y evitar que el juez se apropie del proceso. Paradójicamente, dada la evolución de la aplicación de estas reforzadas potestades judiciales oficiosas parece ser la hora no solo de la delimitación de las potestades de los jueces, sino que de la recuperación de las partes y sus abogados, para el proceso y la Justicia.

\section{4) CUESTIONES EN JUEGO EN RELACIÓN AL RECURSO DE NULIDAD LABORAL: ENCORSETADOS BAJO LA EXCUSA DE LA TUTELA DE LA INMEDIACIÓN JUDICIAL}

En nuestro país, la cuestión de la adopción de procesos orales en sustitución de los escriturados ha dado pie a un particular debate en cuanto al sistema de recursos que se considera compatible con el modelo procesal oral. Así aconteció en primer término con la reforma procesal penal; así aconteció también con la reforma procesal laboral. Así ha sido también con la reforma procesal civil, actualmente en tramitación en el Congreso Nacional.

En efecto, desde hace años se ha destacado la necesidad ineludible de lograr establecer un sistema que resulte compatible técnicamente con las particularidades de un modelo oral, cambiando el paradigma tradicional del recurso de apelación. Esta compatibilidad se lograría solo con la su-

Una cosa es pensar la apuesta por la oralidad en el contexto de un modelo respetuoso de la imparcialidad judicial, del derecho de defensa y donde la información que se inserta al proceso es suficientemente depurada por la actuación de las partes, a partir de una contradicción garantizada debidamente. Y otra bien distinta es pensarla en un contexto donde el reforzado actuar de los jueces no tiene límites efectivos, quedando abierta la puerta a la arbitrariedad judicial que se instala con un juez sin explícitos contrapesos, que no asegura la depuración adecuada de la información que servirá de sustento a la sentencia.

60 Bien se ha dicho que la implementación de un sistema oral, por más atenuado que se presente el principio dispositivo, no puede acarrear la afectación de garantías mínimas que debe tener un litigante en un proceso, por la vía de (mal) entender que dichos poderes son absolutos. El propósito de alcanzar un reconocimiento idóneo del derecho a la tutela jurisdiccional efectiva, no autoriza a dejar de lado el respeto de las garantías mínimas dentro de un proceso VIDAL, M. "Oralidad y garantías constitucionales en el proceso laboral". En: Priori, G. (Editor). Proceso y Constitución. Lima: Ara Editores, 2011, pp. 287 y 288. 
presión de la doble instancia y la regulación de un recurso extraordinario, circunscrito a la revisión de la aplicación del derecho por parte del tribunal superior, sin poder alterar la base fáctica de la decisión del tribunal ${ }^{61}$, condición indispensable para lograr conciliar el sistema recursivo con los "principios del derecho procesal moderno" que se imponen de la mano de la opción por la oralidad.

La razón fundamental que se ha planteado en torno a esta idea de descartar el recurso de apelación del ámbito de un modelo procesal oral como lo es el nuevo proceso laboral, ha sido la tutela de la inmediación judicial que se busca gobierne la nueva forma de enjuiciamiento laboral recuperando, como se ha dicho antes, la figura del juez, en especial en lo que dice relación con la intervención directa en la recepción de las pruebas sobre las cuales el juzgador debe sostener su decisión final. Se sostiene que autorizar un recurso de apelación contra la sentencia dictada en un juicio oral implicaría permitir que la decisión del tribunal más débilmente informado (por no haber tenido contacto directo con la prueba) se impusiera frente a la decisión del tribunal que ha sido directamente informado.

En otras palabras, como se ha dicho reiteradamente por los laboralistas, "el régimen general de impugnación debe descansar sobre el establecimiento de recursos destinados a revisar la validez de las resoluciones, impidiendo que un tribunal que no ha conocido o recepcionado la prueba emita un pronunciamiento sobre las cuestiones de hecho discutidas en el juicio, las que quedan definitivamente asentadas por el $a$ quo, pudiendo solo ser variadas si en su establecimiento se han vulnerado las leyes reguladoras de la prueba, es decir, descansa sobre la violación específica de determinadas normas jurídicas"62.

Con los ańos y la experiencia acumulada nos hemos convencido que los planteamientos como los que anteceden parten de una concepción de la inmediación claramente idealizada, que desde hace algún tiempo se ha venido dejando de lado por la mejor doctrina que se ha apartado del discurso de la inmediación como la panacea a todos los males de la

61 Véase al respecto: Beceña, F. "Sobre la instancia única o doble en el proceso civil". Revista de Derecho Privado, N²34, 1933; Allorio, E. "Sul doppio grado del processo civile". En Studi in onore di Enrico Tulio L. Milano: Giuffré Editore, T. III, 1979; Pizzorusso, A. "Sul principio del doppio grado di giurisdizione". Rivista di Diritto Processuale, 1978; RicCi, E. "Il doppio grado di giurisdizione nel processo civile". Rivista di Diritto Processuale, 1978; De la Oliva, A. "El derecho a los recursos: los problemas de la única instancia". Revista Tribunales de Justicia, Nº101, 1997; González, M. El derecho al recurso en el Pacto de San José de Costa Rica. Córdoba: Editora Lerner, 2004; NúÑEZ, R. "Crónica sobre la reforma del sistema procesal civil chileno (fundamentos, historia y principios)". Revista de estudios de la Justicia, $\mathrm{N}^{\circ}$ 6, 2005; Palomo, D. "Apelación, doble instancia y proceso civil oral. A propósito de la reforma en trámite". Revista de Estudios Constitucionales, №2, 2010.

62 Véase: Lanata, G. "¿Puede el juez lograr el conocimiento exigido por la ley si no ha recibido la prueba?”. Revista Laboral Chilena, №191, 2010. 
Justicia $^{63}$. Suele repetirse que la fórmula de los juicios orales (con inmediación judicial y concentración) permite arribar a una verdad procesal de superior calidad, justamente facilitada por el contacto directo y frontal del juez con las fuentes de prueba, en particular con las fuentes de prueba de carácter personal, como lo es la testimonial o la declaración de partes. La presencia efectiva del juez en la práctica de las actuaciones probatorias y la efectiva proscripción de la delegación situaría al órgano judicial en las mejores condiciones de conocer el objeto del proceso ${ }^{64}$ : "la ausencia de intermediarios que puedan distorsionar, voluntaria o involuntariamente lo transmitido, aporta al órgano juzgador una posición óptima para ponderar todos los elementos y valorarlos correctamente, sobre todo si se tiene en cuenta el sistema probatorio de libre valoración de la prueba donde la inmediación juega un papel esencial al permitir la aplicación de las reglas de la sana crítica sin influencias de intermediarios" 65 .

Al hilo de lo anterior se sostiene el argumento de que no resulta posible para los tribunales superiores, salvo la constatación de razonamientos absurdos y groseros, revisar la valoración de la prueba llevada a cabo por el tribunal de la instancia, porque el que conoce a través del recurso no ha oído con sus oídos ni ha visto con sus ojos la prueba ${ }^{66}$. Al señalar esto se olvida que aunque mucho hay que reconocer de positivo en el contacto directo y frontal del juez con las fuentes de prueba, los resultados que arroja ese contacto no son infalibles ${ }^{67}$.

Se centra todo en un problema de credibilidad o fiabilidad, según el cual la inmediación existente en la recepción probatoria se convierte en los hechos en una especie de peligroso blindaje del juicio fáctico y las eventuales arbitrariedades puedan verificarse ${ }^{68}$, esquivándose de paso una

63 Véase especialmente: ANDRÉs, P. "Sobre el valor de la inmediación (una aproximación crítica)". Revista Jueces para la Democracia, N46, 2003; Nieva (2010).

"Mientras más inmediata la percepción, mayor calidad de la misma". Duce/Marín/Riego (2008).

65 Véase: Herrera, R. La inmediación como garantía procesal (en el proceso civil y en el proceso penal). Granada: Ed. Comares, 2006.

66 "La oralidad, la publicidad, la contradicción y sobre todo la inmediación representan las ventajas del proceso celebrado a presencia de los jueces que ven y oyen lo que ya después otros ojos y oídos no percibirán". Véase: Herrera (2006).

67 Bien se ha señalado que aun reconociéndose una mejor posición del juez para decidir la credibilidad o fiabilidad de determinada fuente de prueba (gracias a la inmediación), debe puntualizarse que la inmediación que efectivamente es la regla de mayor peso a la hora de la apreciación de la prueba y de la formación del convencimiento, no debe ser elevada necesariamente a un absoluto. Del Río, C. "Consideraciones básicas sobre el sistema de prueba en materia penal y control sobre el núcleo fáctico mediante recurso de nulidad (y II)”. Revista Internauta de Práctica Jurídica, No 9, 2002.

68 Bien se ha advertido que hay que proveer las herramientas necesarias para que la oralidad y la inmediación puedan servir sin excesos, puesto que, de lo contrario, en algunos casos provocan todavía más arbitrariedades que las muchísimas que se producían y se producen con la práctica escrita de la prueba. Véase: Nieva (2010). 
motivación más exhaustiva que dé efectivamente cuenta de la racionalidad de la decisión que se ha adoptado ${ }^{69}$ y consagrándose una noción subjetivista de la prueba, que termina vinculándola con la creencia del tribunal, desconociendo las exigencias propias de un sistema de valoración de la prueba libre, conforme a las reglas de la sana crítica $^{70}$ derivando así la libertad en una valoración irracional, en arbitrariedad, en sacrificio de la verdadera motivación ${ }^{71}$ y en una renuencia de los tribunales superiores a revisar la valoración probatoria ${ }^{72}$, incluso bajo el ámbito de aquella causal que le autoriza a fiscalizar si se han vulnerado las leyes reguladoras de la prueba, reservado solamente para infracciones manifiestas, como acontece tratándose del recurso de nulidad de acuerdo a lo prescrito por el artículo 478 del Código del Trabajo ${ }^{73}$.

De algún modo se termina operando con la equivocada lógica de que los procedimientos procesales de conocimiento de los hechos proporcionan resultados infalibles, solo susceptibles de ser revisados en casos absurdos y groseros, limitando drásticamente las posibilidades de revisión efectiva por parte del tribunal superior. Algunos autores, constatadas estas dificultades y excesos, comienzan a señalar a la inmediación como un factor de contaminación subjetiva del juez ${ }^{74}$, lo que resulta especialmente

Taruffo habla de la motivación como garantía de racionalidad y de controlabilidad de las pruebas, haciendo posible un juicio posterior sobre las elecciones del juez en materia de valoración probatoria. Véase: ANDRÉs (2007).

71 Parece no entenderse cabalmente entre nosotros: la valoración libre de la prueba no implica que dicha valoración sea arbitraria, caprichosa o irracional. Las reglas de la sana crítica se alzan como el camino a seguir en la valoración de las pruebas rendidas, que deben servir para su crítica o depuración. Se trata de normas empíricas sostenidas en la razón, la madurez, el buen sentido lógico y el sano juicio. Se trata, en definitiva, de una valoración razonada, motivada y responsable. Si bien el juez se hace con un mayor protagonismo, no puede ni debe entenderse como una especie de patente de corso para despegarse de las exigencias propias de una resolución debidamente razonada y motivada.

72 Esta situación ha merecido críticas también en el ámbito penal, donde el recurso de nulidad muestra similares restricciones en su aplicación. Véase: AcCaTino, D. "Forma y sustancia en el razonamiento probatorio. El alcance del control sobre la valoración de la prueba a través del recurso de nulidad penal". Revista de derecho Pontificia Universidad Católica de Valparaiso, $\mathrm{N}^{\circ} 1$, 2009; AcCatino, D. "El modelo legal de justificación de los enunciados probatorios en las sentencias penal y su control a través del recurso de nulidad". En: Accatino, D. (Coord.). Formación y valoración de la prueba en el proceso penal. Santiago: Ed. Abeledo Perrot, 2010.

73 Dispone el artículo 478: El recurso de nulidad procederá, además: b) Cuando haya sido pronunciada con infracción manifiesta de las normas sobre la apreciación de la prueba conforme a las reglas de la sana crítica".

74 Gumerato, G. "Repensando a prova de oficio". En: Hernández, G. (Editor). Actualidad y futuro del Derecho procesal: principios, reglas y pruebas. Bogotá: Ed. Universidad de Rosario, 2010 , pp. 152 y ss. “... la inmediación contamina el juicio de la persona física (juez) responsable de la dictación de la sentencia de mérito. El juez, debido a su elemental condición humana, y como sujeto integrante de la oralidad propia del procedimiento probatorio, invariablemente va siendo afectado por las impresiones subjetivas que las actitudes de los deponentes (partes, testigos, peritos) le sugieren. Y como reflejo de la inquisitividad que 
atingente cuando se trata de un juez que actúa sin haberse previsto límites claros a sus potestades.

No compartimos una visión restringida de la impugnación del juicio fáctico en el nuevo proceso laboral ${ }^{75}$, ni menos cuando se sostiene que se justifica por la celeridad que requiere la Justicia laboral ${ }^{76}$. Y no lo compartimos fundamentalmente porque sostenemos una visión de los recursos que no pone la atención en su calidad de mecanismos de control jerárquico, sino que en su condición de garantías para los justiciables contra la arbitrariedad y errores que puedan cometer los tribunales en su actividad, con el agravante de que en los juicios laborales nos encontramos muchas veces, como se explicó antes, con jueces que actúan sin límites ni contrapesos, que se creen autorizados para pasar por encima de las garantías de las partes, con desprecio a la imparcialidad, la igualdad de armas, la contradicción y el derecho de defensa.

El recurso de nulidad, recurso extraordinario, no satisface a nuestro juicio el estándar del recurso como una garantía ${ }^{77}$, donde su aplicación práctica, tanto en sede procesal penal como en sede procesal laboral, ha mostrado la irrupción de criterios muy restrictivos que se suman a un excesivo rigor formal que junto con ser incongruentes con la aspiración de ganar en desformalización que rodea la apuesta por la oralidad en los juicios, atenta contra la garantía del derecho al recurso ${ }^{78}$, lo que resulta aún menos presentable tras algunos pronunciamientos de la Corte Intera-

marca la actuación del juez en la práctica de la prueba, sus impresiones personales influirán en el modo que el juez conducirá la fase de prueba de los hechos y luego en el juzgamiento de mérito que inmediatamente, este mismo juez, deberá realizar”. En suma, lo que se postula en definitiva, es que su condición humana va de la mano de la falibilidad, la que debe ser morigerada por el debido proceso legal.

75 Véase: Tapia, F. "Admisibilidad del recurso de nulidad laboral". Revista Laboral Chilena, $\mathrm{N}^{\circ} 188,2010$

76 Pretender que razones de celeridad son suficientes para abordar una reforma restrictiva del sistema recursivo es prescindir de elementos fundamentales que deben ser necesariamente considerados. Expresivamente se ha sentenciado: "Problemas de esta especie no se resuelven solo con el calendario". AlLorio (1979).

77 Y ya se ha observado por la doctrina: "El carácter ordinario o extraordinario del recurso incide de manera diversa sobre el acceso a la tutela judicial efectiva mediante el recurso": Lorca, A. Tratado de Derecho Procesal Civil. Parte General: El nuevo proceso civil. Madrid: Ed. Dykinson, 2000. Tratándose de la realidad de nuestro recurso de nulidad en el proceso laboral, el logro de la tutela judicial efectiva es menos penetrante que si se tuviera acceso al recurso de apelación.

78 Entre las razones que están detrás de esta realidad jurisprudencial es que las restricciones y mayor rigor formal estarían justificadas precisamente por tratarse de un recurso extraordinario, de derecho estricto, en donde la elevación de los requisitos formales está en función de garantizar la excepcionalidad del recurso. Todo ello, en el marco de una jurisprudencia que sistemáticamente advierte que a través de este recurso no es posible inmiscuirse en las cuestiones de hecho establecidas por el tribunal de la instancia, impedimento que encuentra justificación en el hecho de que se frustraría la finalidad misma para la que fue instaurada la inmediación, perdiéndose la posición privilegiada del tribunal del juicio oral respecto del tribunal de alzada y transformándose el recurso en cuestión en una nueva instancia. 
mericana de Derechos Humanos (caso Herrera Ulloa con Costa Rica) en el cual la Corte señala que independientemente de la denominación que se dé al recurso existente para recurrir una sentencia, lo importante es que dicho recurso garantice un examen integral de la decisión recurrida, tanto en los errores de hecho como de derecho ${ }^{79}$.

La pregunta es si la regulación y práctica del recurso de nulidad laboral garantizan este examen lo suficientemente integral de la decisión impugnada, en las cuestiones de hecho como de derecho. Por las razones antes apuntadas creemos que la respuesta a esta pregunta es negativa toda vez que según se ha señalado nuestras Cortes de Apelaciones no tocan el enjuiciamiento fáctico, salvo que la valoración del juez sea absurda o groseramente opuesta a las reglas de la sana crítica, amparándose precisamente en el respeto a la inmediación judicial. Esto resulta bastante preocupante si se tiene a la vista el principal objetivo de la reforma procesal laboral, cual es lograr mayor eficiencia en los tiempos de respuesta, una Justicia que se quiere rápida, por lo tanto más expuesta a cometer errores.

A nuestro juicio, siguiendo en este punto a Picó i Junoy ${ }^{80}$, en un sistema recursivo adecuado, los tribunales superiores de justicia no debieran limitarse a corregir errores manifiestos o groseros en los tribunales inferiores, sino que en la búsqueda de la solución más acertada y justa para los justiciables, debiera valorar de nuevo la prueba, sin estar vinculado a lo razonado y valorado por el juez inferior, abarcando la revisión todo el material fáctico y jurídico ${ }^{81}$. Con todo, esta posibilidad no ha tenido ni puede tener cabida en el contexto del recurso de nulidad, ni aun con los esfuerzos interpretativos de la doctrina que han buscado optimizar las escasas rendijas que deja la regulación de manera de evitar que la restricción del sistema sea incompatible con el derecho al recurso ${ }^{82} 83$.

79 Ya resulta pacífico que las garantías procesales del artículo 8 del Pacto de San José de Costa Rica se deben entender extendidas a todos los órdenes jurisdiccionales. El fallo de la Corte Interamericana de Derechos Humanos en el caso Baena Ricardo con Panamá (2001) abrió la ruta en esta dirección.

80 Véase: Picó i Junoy, J. "Valoración de la prueba y segunda instancia civil: hacia la búsqueda del necesario equilibrio”. Revista Jurídica de Catalunya, N³, 2009.

81 Bien se ha señalado que no parece equilibrado asignar solamente a una de las fases del enjuiciamiento, el establecimiento y fiscalización de los hechos. Véase: Pereira, H. "La prueba en el recurso de apelación civil". Revista de Derecho y Jurisprudencia, No6, 1965.

82 La cuestión apareja consecuencias. "El carácter ordinario o extraordinario del recurso incide de manera diversa sobre el acceso a la tutela judicial efectiva mediante el recurso". Cuando el sistema recursivo permite que conjuntamente con el recurso ordinario (apelación), se pueda acceder a otra instancia procesal ad quem mediante el recurso extraordinario, la tutela judicial efectiva es más determinante. En cambio, cuando el sistema impone que se pase directamente a la vía extraordinaria, sin existir un acceso previo a la vía ordinaria del recurso, el logro de la tutela judicial efectiva es claramente menos incisiva y penetrante. Véase: LorCA (2000).

83 La restricción existente claramente no resulta fácil de entender, menos, como ha precisado Cristián Maturana, cuando el Estado ha invertido importantes sumas en dotar a los tribu- 
Esta insatisfacción con las deficiencias mostradas por el recurso de nulidad ha derivado en que se esté postulando una reforma que plantea reintroducir al proceso laboral el recurso de apelación contra la sentencia definitiva (Boletín No 6.970-13), propuesta considerada un retroceso desde la doctrina laboral (muy entusiasmada por las estadísticas que arroja el sistema), pero que pretende hacerse cargo de los problemas que viene aparejando el blindaje de una sentencia pronunciada por un tribunal unipersonal que, añadidamente, goza de reforzadas potestades que al día de hoy no cuentan con los debidos contrapesos y límites, a través del restablecimiento del recurso de apelación, que permita una revisión lo suficientemente amplia.

En definitiva, dada la experiencia recogida en los años de aplicación de esta reforma procesal sería conveniente asumir con seriedad y enfoque crítico su evaluación desde una perspectiva específica y general. Específica, desde lo que es su naturaleza, que en los hechos se traduce para nuestras Cortes como un recurso extraordinario y excepcional, que cierra formalizadamente un proceso oral que, paradójicamente, tiene entre sus pilares la huida de la formalización tan propia del modelo escriturado. Y general, desde las dudas y los cuestionamientos que nos plantea el proceso de conformación y generación de la respuesta jurisdiccional que se levanta sobre la base de un protagonismo desbordado del juez que, a la fecha, solo se encuentra limitado, en el mejor de los casos, por su propia prudencia, que debiera ser propia del actuar judicial. Mientras la prudencia siga perdiendo fuerza en favor de una difusa meta justiciera, el resultado seguirá en deuda de cara a identificar un verdadero proceso y no un mero procedimiento cuando a la Justicia laboral nos estamos refiriendo: jueces que en su actuación reforzada abren paso a la arbitrariedad judicial, que se apoderan del proceso y actúan abiertamente como partes, abogados paralizados frente a este protagonismo desmedido, sentencias insuficientemente motivadas a pesar de las exigencias de la sana crítica, primando una noción subjetivista de la prueba, y un sistema recursivo que se cierra y formaliza cada vez más, impidiendo que esa respuesta jurisdiccional, generada en ese contexto, pueda ser suficientemente revisada.

\section{5) CONCLUSIONES: UN MODELO QUE REQUIERE CAMBIOS A PARTIR DE LA RECUPERACIÓN DEL EQUILIBRIO}

Dejamos para el cierre conclusivo cuatro ideas finales, que no son otra cosa que una invitación a buscar el equilibrio en un modelo que en

nales de un sistema de registro de audio que pierde toda razón de ser si priman postulados como los vigentes que señalan que no se puede, salvo excepciones muy calificadas, revisar lo acontecido en el juicio. Los registros están allí y deben ser utilizados, si de verdad se quiere evitar que la búsqueda de la eficiencia se haga a costa de las garantías. 
el afán de cambiar la Justicia laboral está permitiendo la materialización de una serie de problemas que no solo están afectando la situación de la noción misma de proceso en este ámbito, sino que la propia imagen de la seriedad objetiva de la Justicia reformada bajo la idea central de la oralidad:

a) La asunción de un modelo oral ha contribuido en la dirección de rescatar y revalorizar la actividad más relevante de todo proceso, también los laborales: la prueba. Sobre la base de asegurar efectivamente la inmediación del juez en los momentos claves de la prueba (proposición y práctica), se ha buscado recuperar su seriedad e importancia. Esta recuperación, para concretarse definitivamente, requiere de una actuación judicial activa, pero debidamente controlada por los abogados de las partes. Entrando los jueces tempranamente en contacto directo con la causa, las partes y sus abogados, pueden adoptar de entrada las mejores decisiones que permitan orientar y conducir el proceso a una decisión adecuada de la controversia planteada por las partes del juicio. La experiencia acumulada hasta ahora en el terreno de la aplicación del nuevo sistema evidencia la necesidad de corregir algunos problemas de funcionamiento de las audiencias que por un lado impiden sacar los mejores frutos de las mismas, y por el otro comprometen elementos esenciales de la noción misma de proceso garantizada por la propia Constitución.

b) El entendimiento de las exigencias y deberes que impone el nuevo modelo aún no es homogéneo ni entre jueces ni entre abogados, lo que impone seguir trabajando en la consolidación de un esquema de enjuiciamiento que obliga a los distintos operadores a un cambio de hábitos y a una especial capacitación. Especial mención a las dificultades que se han evidenciado en la práctica forense de cara a las posibilidades que brinda la litigación oral. La recuperación de la figura del juez, debe ir de la mano de la debida intervención de los abogados, que para ello requieren estar especialmente preparados tanto desde la perspectiva sustancial ligada a la materia involucrada en estos juicios como en lo que dice relación con los conocimientos, destrezas y técnicas específicas que impone un modelo procesal oral, que no puede quedar totalmente entregado en su suerte a lo que el juez de turno disponga. De no tomar en serio esta necesidad de capacitación de los abogados, seguirá siendo una costumbre, peligrosa, la situación en la cual los jueces se terminan apoderando del proceso, con abogados que se paralizan frente a decisiones y actuaciones judiciales que claramente deben ser controladas y limitadas.

c) Los reforzados poderes oficiosos que se asignan por la ley a los jueces no siempre han encontrado la debida prudencia en su ejercicio concreto. Al contrario más bien, si se atiende al dato de la realidad forense, no siempre adecuadamente visible. Si bien no resulta sencillo plantear la necesidad de introducir cambios a un modelo que exhibe unas estadísticas 
ligadas al tiempo de respuesta que casi encandilan, somos de aquellos que postulan que en Derecho la consecución de unos determinados objetivos no pueden autorizar la utilización de cualquier medio para obtenerlos. En un escenario que cada día muestra más conductas reñidas con la debida imparcialidad judicial, con el derecho constitucional de defensa, con los principios básicos de contradicción e igualdad, abriendo la puerta a la arbitrariedad judicial y comprometiendo la calidad y fiabilidad de la información que se incorpora al proceso, se hace necesario poner fin a actuaciones que comienzan a reproducirse en los tribunales del trabajo y que poco dignifican la labor judicial imparcial y mucho dañan la imagen de la Justicia, partiendo por reconocer siempre a las partes, representadas por sus abogados, desde el resguardo absoluto de la contradicción, las garantías para su derecho de defensa, en adecuado equilibrio frente a las reforzadas potestades judiciales.

d) Finalmente, vendría siendo hora de dejar atrás el excesivo idealismo con que algunos abordan el tema de la relación entre la inmediación judicial que se recoge en la nueva normativa y el sistema recursivo. Cabe asumir los problemas que la práctica forense viene evidenciando en la aplicación del recurso de nulidad laboral, a fin de lograr que el recurso al que accedan las partes sea lo suficientemente amplio como para permitir la revisión de los hechos y del derecho, sin seguir expuestos a variadas interpretaciones restrictivas propias de un recurso de derecho estricto y excepcional motivadas, en el mejor de los casos, en un absoluto respeto a lo establecido, con inmediación, por el juez de la instancia. Huelga que insistamos en los evidentes peligros de esta fórmula recursiva excesivamente restrictiva diseñada en el marco de un modelo que plantea un juez dotados de reforzadas potestades, sin los mínimos resguardos o contrapoderes para las partes que permitan un control oportuno de estas, y que además, en general, no viene satisfaciendo adecuadamente el estándar de motivación que debe imponer un sistema de valoración conforme a las reglas de la sana crítica, lo que termina sirviendo de excusa a las restrictivas posibilidades de control de lo resuelto por parte del tribunal superior, contrariando los requerimientos derivados del derecho de defensa y del derecho al recurso.

\section{BibLIOGRAFÍA}

- Accatino, D. "Forma y sustancia en el razonamiento probatorio. El alcance del control sobre la valoración de la prueba a través del recurso de nulidad penal". Revista de Derecho de la P. Universidad Católica de Valparaíso, XXXII, 2009. 
"El modelo legal de justificación de los enunciados probatorios en las sentencias penal y su control a través del recurso de nulidad". En: Accatino, D. (Coord.). Formación y valoración de la prueba en el proceso penal. Santiago: Ed. Abeledo Perrot, 2010.

, "La publicidad de las razones judiciales". En:

Romero, A. Estudios de Derecho en Homenaje a Raúl Tavolari Oliveros. Santiago: Ed. LexisNexis, Instituto Chileno de Derecho Procesal, 2007.

- Aguilera, R. Proceso laboral y proceso civil: Convergencias y divergencias. Madrid: Ed. Thomson/Civitas, 2004.

- Allorio, E. "Sul doppio grado del processo civile". En Studi in onore di Enrico Tulio L. Milano: Giuffré Editore, T. III, 1979.

- Alvarado, A. Garantismo procesal contra actuación judicial de oficio. Valencia: Ed. Tirant lo Blanch, 2005.

, La prueba judicial: reflexiones sobre la confirmación procesal. Santiago: Ed. Librotecnia, 2009.

- Alvarado, A.; Zorzoli, O. (Directores). El debido proceso. Buenos Aires: Ediar, 2006.

- Andrés, P. "Sobre el valor de la inmediación (una aproximación crítica)". Revista Jueces para la Democracia, N46, 2003.

- Araya, M. Los hechos en el recurso de nulidad en materia penal. Santiago: Ed. Abeledo Perrot, 2011.

- Barbosa, J. "La significación social de las reformas procesales". Revista de processo, 131, 2006.

- Beceña, F. "Sobre la instancia única o doble en el proceso civil". Revista de Derecho Privado, N²34, 1933.

- Bordalí, A.; Hunter, I. "Revisión crítica de la oralidad en los juicios en Chile”. Microjuris, MJCH_MJD2/MJD402, 2010.

- Cappelletti, M. "Processo orale e processo scritto nel mondo contemporaneo". En: Cappelletti, M. Giustizia e Societá. Milano: Edizioni di Comunitá, 1972.

- Carnelutti, F. Lezioni di Diritto Processuale Civile. Padova: Cedam, III, 1921.

- Carocca, A.; y otros. Nuevo proceso penal. Santiago: Ed. Jurídica ConoSur, 2000.

- Carocca, A. Derechos Humanos y derecho civil: perspectiva procesal. Santiago: CPU, 1997.

Garantía Constitucional de la Defensa Procesal. Barcelona: Editorial J. M. Bosch, 1998.

- Carofiglio, G. El arte de la duda. Madrid, Ed. Marcial Pons, 2010.

- Carpi, F.; Ortells, M. Oralidad y escritura en un proceso civil eficiente. Valencia: Universidad de Valencia, 2008. 
- Cavallone, B. Il giudice e la prova nel processo civile. Padova: Cedam, 1997.

- Cerda, R. Valoración de la prueba: Sana crítica. Santiago: Ed. Librotecnia, 2008.

- Cipriani, F. Stato di diritto e garanzie processuali: atti delle II Giornate internazioni di Dirito processuale civile. Napoli: Edizioni Scientifiche Italiane, 2008.

- Chinrloni, S. "Reflexiones microcomparativas sobre ideologías procesales y comprobación de la verdad". Revista Internauta de Práctica Jurídica, $\mathrm{N}^{\circ} 24,2009$.

- Chiovenda, G. "L'oralitá e la prova". Rivista di Diritto Processuale Civile, Vol. I, 1924.

- Cortez, G. El recurso de nulidad: doctrina y jurisprudencia. Santiago: Ed. LexisNexis, 2006.

- Damaska, M. Il diritto delle prove alla deriva. Bologna: Ed. il Mulino, 2003.

- De la Oliva, A. "El derecho a los recursos: los problemas de la única instancia". Revista Tribunales de Justicia, N¹01, 1997.

- De la Oliva, A. y otros. Derecho procesal: introducción. Madrid: Ed. Ramón Areces, 2004.

- Del Río, C. "Revisión de los hechos mediante recurso de nulidad". En VV.AA. Seminario Reforma procesal penal. Santiago: Ed. ConoSur, 2001.

- Denti, V. "Chiovenda y las reformas del proceso civil". En: Sendra, V. y otros (Coords.). Estudios de Derecho Procesal en honor de Victor Fairén Guillén. Valencia: Ed. Tirant lo Blanch, 1990.

- Dinamarco, C. La instrumentalidad del proceso. Lima: Ed. Communitas, Traducción de José Monroy P., 2009.

- Duce, M.; Riego, C. Proceso penal. Santiago, Ed. Jurídica de Chile, 2007.

- Duce, M.; Marín, F.; Riego, C. "Reforma a los procesos civiles orales: consideraciones desde el debido proceso y calidad de la información". En: Cabezón, A. (Coord.). Justicia civil: perspectivas para una reforma en América Latina. Santiago: Ceja - Jsca, 2008.

- Fairén, V. La audiencia previa: consideraciones teórico-prácticas. Madrid: Ed. Civitas, 2000.

- Fazzalari, E. "La imparzialitá del giudice". Rivista di Diritto Processuale, 1972.

- Fernández, R. Las facultades y deberes del juez en materia probatoria en el proceso laboral: análisis crítico". Santiago: Ed. Puntolex, 2011.

- Flores, Á. "La reforma a la Justicia del Trabajo". Revista Laboral Chilena, 2006. 
- García, G. "Los principios informadores del proceso laboral (algunas reflexiones críticas en torno a la oralidad, celeridad y concentración)". En: De la Serna, M. y otros. El proceso laboral: Estudios en Homenaje al profesor Luis Enrique de la Villa Gil. Valladolid: Ed. Lex Nova, 2001.

- García, S. "El debido proceso en la jurisprudencia de la Corte Interamericana de Derechos Humanos". En: Tavolari, R. (Director). Derecho procesal contemporáneo: ponencias de las XII Jornadas Iberomericanas de Derecho Procesal. Santiago: Ed. Jurídica de Chile, 2010.

- González, M. El derecho al recurso en el Pacto de San José de Costa Rica. Córdoba: Editora Lerner, 2004.

- Gozaíni, O. Problemas actuales de Derecho procesal (Garantismo vs activismo). Santiago de Querétaro: Ed. Fundap, 2002.

- Gumerato, G. "Repensando a prova de oficio". En: Hernández, G. (Editor). Actualidad y futuro del Derecho procesal: principios, reglas y pruebas. Bogotá: Ed. Universidad de Rosario, 2010.

- Horvitz, M. Inés. "Acerca de la garantía del condenado de recurrir en contra de la sentencia condenatoria". Informes en Derecho, Centro de Documentación Defensoría Penal Pública, N6, 2009.

- Humeres, H. "La reforma al procedimiento contemplado en el Código del Trabajo". Revista Actualidad Jurídica, N¹4, 2006.

- Humeres, H. "Los recursos de nulidad y unificación: un apunte foral". Revista Chilena de Derecho del Trabajo y de la Seguridad Social, Universidad de Chile, Vol. I, N² 2, 2010.

- Hunter, I. Las potestades probatorias del juez de familia. Santiago: Ed. LegalPublisching, 2009.

, "Poderes del juez civil: algunas consideraciones a

propósito del juez de familia”. Revista de Derecho, Universidad Austral de Chile, Vol. XX, Nº1, 2007.

- Lanata, G. El sistema de recursos en el proceso laboral chileno. Santiago: Ed. Abeledo Perrot, 2011. , "PPuede el juez lograr el conocimiento exigido por la ley si no ha recibido la prueba?”. Revista Laboral Chilena, $\mathrm{N}^{\circ} 191,2010$.

- Leturia, F. (Ed.). Justicia civil y comercial: una reforma ¿cercana? Santiago: P. Universidad Católica de Chile, U. Diego Portales y U. del País Vasco, 2011.

- Lorca, A. El Derecho procesal conceptuado a través de la metodología del garantismo procesal. San Sebastián: Ed. Dijusa, 2009.

Tratado de Derecho Procesal Civil. Parte General: El nuevo proceso civil. Madrid: Ed. Dykinson, 2000. 
- Luco, N. "¿De vuelta al sistema inquisitivo?. En: Leturia, F. (Ed.). Justicia civil y comercial: una reforma ¿cercana? Santiago: P. Universidad Católica de Chile, U. Diego Portales y U. del País Vasco, 2011.

- Nieva, J. "Los problemas de la oralidad". Revista justicia, $\mathrm{N}^{\circ} 1-2$, 2007.

_ ___ _ _ _ _ _ _ _ _ _ nalidad e inmediación en la prueba: luces y sombras". Civil Procedure Review, Vol. I, N², 2010.

- Mazzoni, G. ¿Se puede creer a un testigo? el testimonio y las trampas de la memoria. Madrid: Ed. Trotta, 2010.

- Montero, J. "Del Derecho procesal al Derecho jurisdiccional", Revista Justicia, NII, 1984.

_ _ _____________ L principios políticos de la nueva Ley de Enjuiciamiento Civil: los poderes del juez y la oralidad. Valencia: Ed. Tirant lo Blanch, 2001.

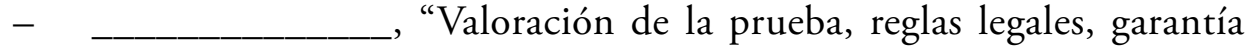
y libertad en el proceso civil". En: Cipriani, F. Stato di diritto e garanzie processuali: atti delle II Giornate internazioni di Dirito processuale civile. Napoli: Edizioni Scientifiche Italiane, 2008. de funciones procesales. Valencia: Ed. Tirant lo Blanch, 1999. , (Coord.). Proceso civil e ideología: un prefacio, una sentencia, dos cartas, quince ensayos y moción de Valencia". Santiago: Ed. Metropolitana, 2008.

- Nogueira, H. El debido proceso en la Constitución y el sistema interamericano. Santiago: Ed. Librotecnia, 2007.

- NovoA, P.; y otro. "Reforma procesal laboral: procedimiento de aplicación general". Revista Laboral Chilena, Nº166, 2008.

- NúŃEz, R. "Crónica sobre la reforma del sistema procesal civil chileno (fundamentos, historia y principios)". Revista de estudios de la Justicia, N6, 2005. Oberg, H. "Apelación laboral". Revista de Derecho Universidad de Concepción, año LXXIII, N²17-218, 2005.

- Ortells, M. Derecho procesal: introducción. Valencia: Ed. Punto y Coma, 2003.

- __ "Prólogo". En: Bonet, J. La prueba en el proceso civil: cuestiones fundamentales. Madrid, Ed. Difusión jurídica, 2009.

- Palavecino, C. "El retorno del inquisidor. Las potestades judiciales en materia probatoria en el procedimiento laboral chileno". Revista Laboral Chilena, $\mathrm{N}^{\circ} 173,2009$.

- Palomo, D. La oralidad en el proceso civil: el nuevo modelo español. Santiago: Ed. Librotecnia, 2008.

_ _ _ _ _ _Las marcas del proceso oral y escrito diseńado en el Proyecto de nuevo CPC". Revista Chilena de Derecho, 2009. 
"Apelación, doble instancia y proceso civil oral. A propósito de la reforma en trámite". Revista Estudios Constitucionales, $\mathrm{N}^{\circ} 2,2010$.

- Palomo, D.; Matamala, P. "Los problemas de los poderes ex officio del juez laboral. Ahora a propósito de la potestad conciliatoria". Revista Ius et Praxis, N¹, 2012.

- Pellegrini, A. "Modernitá del diritto processuale brasiliano". En: VVAA. Scritti in onore di Elio Fazzalari. Milano: Ed. Giuffré, Vol. II, 1993.

- Pereira, H. "Oralidad e instancia única o doble en el proceso penal”. Revista Gaceta Jurídica, N²33, 1999.

- Pereira, S. El proceso civil ordinario por audiencias: la experiencia uruguaya en la reforma procesal civil. Montevideo: Ed. Amalio M. Fernández, CEJS - JSCA, 2008.

- Peyrano, J. "El perfil deseable del juez civil del siglo XXI". En: Silva, J.; García, J.; Leturia, F. (Coords.). Justicia civil y comercial: una reforma pendiente. Bases para el diseño de la reforma procesal civil. Santiago: P. Universidad Católica de Chile, Universidad Autónoma de Madrid, Instituto Libertad y Desarrollo, 2006.

- Picardi, N. "Riflessioni critiche in tema di oralitá e scrittura". Rivista Trimestrale di Diritto e procedura civile, 1973.

, "Audiatur et altera pars: le matrici storico-culturali del contraddittorio". Rivista Trimestrale di Diritto e Procedura Civile, 2003.

\section{Processuale, 1998.}

"Il principio del contraddittorio". Rivista di Diritto

- Picó, J. "El Derecho procesal entre el garantismo y la eficacia: un debate mal planteado". Revista Iberoamericana de Derecho Procesal, No4, 2004.

_ _ _ ______________ "Los principios constitucionales rectores del proceso civil en Espańa: los principios referentes al objeto del proceso, su dirección y desarrollo formal". Revista Advocatus, $\mathrm{N}^{\circ} 10$, 2004.

Ed. J.M. Bosch, 1997.

Las garantías constitucionales del proceso. Barcelona:

- Pizzorusso, A. "Sul principio del doppio grado di giurisdizione". Rivista di Diritto Processuale, 1978.

- Plá, A. "Visión crítica del Derecho procesal del Trabajo". En: Processo do Trabalho na América Latina: Estudos em homenagem a Alcione Niederauer Correa. São Paulo: Ltr Editora, 1992.

- Priori, G. (Coord.). Proceso y Constitución. Lima: Ed. Ara, 2011

- Ramírez, D. "La oralidad y su relación con los poderes de instrucción que tiene el juez en el proceso". En: Taruffo, M.; 
Ramírez, D. (Dir.). Conocimiento, prueba, pretensión y oralidad. Lima: Ara Editores, 2009.

- Ramos, F. Derecho y proceso. Barcelona: Ed. Bosch, 1978.

- Ricci, E. "Il doppio grado di giurisdizione nel processo civile". Rivista di Diritto Processuale, 1978.

- Ricci, G. Principi di Diritto Processuale Generale. Torino: G. Giappichelli Editore, Seconda edizione, 1998.

- Rodríguez, S. "La oralidad". Revista Gaceta Jurídica, Nº151, 1993.

- Santibáñez, C. "Las cargas probatorias dinámicas". Revista Chilena de Derecho del Trabajo y de la Seguridad Social, Universidad de Chile, $\mathrm{N}^{\circ} 1,2010$.

- Silva, J.; García, J.; Leturia, F. (Coords.). Justicia civil y comercial: una reforma pendiente. Bases para el diseño de la reforma procesal civil. Santiago: P. Universidad Católica de Chile, Universidad Autónoma de Madrid, Instituto Libertad y Desarrollo, 2006.

- TAPIA, C. "Garantismo procesal: un debate ausente y una advertencia clara". Revista Chilena de Derecho del Trabajo y de la Seguridad Social, Universidad de Chile, Vol. I, N², 2010.

- Tapia, F. "El nuevo procedimiento en juicio del trabajo en la Ley 20087/06". Revista de Derecho Social Latinoamérica, N², Buenos Aires, 2007.

_ _ _ "Admisibilidad del recurso de nulidad laboral". Revista Laboral Chilena, $\mathrm{N}^{\circ} 188,2010$.

- Taruffo, M. Páginas sobre justicia civil. Madrid: Ed. Marcial Pons, 2009.

_ ___ "Oralidad y escritura como factores de eficiencia en el proceso civil". En: Carpi, F.; Ortells, M. Oralidad y escritura en un proceso civil eficiente. Valencia: Universidad de Valencia, 2008.

- Tavolari, R. (Dir.). Derecho procesal contemporáneo: ponencias de las XII Jornadas Iberomericanas de Derecho Procesal. Santiago: Ed. Jurídica de Chile, 2010.

- Toro, C. El debido proceso penal: un estudio desde el prisma de la dogmática procesal penal y la jurisprudencia de la Corte Interamericana de Derechos Humanos. Santiago: Ediciones Jurídicas de Santiago, 2009.

- Trocker, N.; Varano, V. (Coords.). The reforms of civil procedure in comparative perspective. Turín: Ed. Giappichelli, 2005.

- Valenzuela, A. "La reforma procesal laboral: de la 'cultura expediente' a la sala de audiencias". Revista Laboral Chilena, $\mathrm{N}^{\circ} 170$, 2008.

- Vescovi, E. "Los poderes probatorios del juez civil en los nuevos sistemas procesales". En: Studi in onore di Vittorio Denti, Padova: Ed. Cedam, Vol. II, 1994. 
- Vidal, M. "Oralidad y garantías constitucionales en el proceso laboral". En: Priori, G. (Editor). Proceso y Constitución. Lima: Ara Editores, 2011.

- VV.AA. Proceso, prueba y estándar. Lima: Ed. Ara, 2009.VVAA. XVIII Jornadas Iberoamericanas - XI Jornadas Uruguayas de Derecho procesal: En Homenaje a la Escuela Procesalista Uruguaya. Montevideo: Fundación de Cultura Universitaria, 2002. 